\title{
Applications of simulation within the healthcare context
}

\author{
$\mathrm{K} \mathrm{Katsaliaki}^{1 *}$ and N Mustafee ${ }^{2}$ \\ ${ }^{1}$ International Hellenic University, Thessaloniki, Greece; and ${ }^{2}$ Swansea University, Swansea, Wales, UK
}

A large number of studies have applied simulation to a multitude of issues relating to healthcare. These studies have been published in a number of unrelated publishing outlets, which may hamper the widespread reference and use of such resources. In this paper, we analyse existing research in healthcare simulation in order to categorise and synthesise it in a meaningful manner. Hence, the aim of this paper is to conduct a review of the literature pertaining to simulation research within healthcare in order to ascertain its current development. A review of approximately 250 high-quality journal papers published between 1970 and 2007 on healthcarerelated simulation research was conducted. The results present a classification of the healthcare publications according to the simulation techniques they employ; the impact of published literature in healthcare simulation; a report on demonstration and implementation of the studies' results; the sources of funding; and the software used. Healthcare planners and researchers will benefit from this study by having ready access to an indicative article collection of simulation techniques applied to healthcare problems that are clustered under meaningful headings. This study facilitates the understanding of the potential of different simulation techniques in solving diverse healthcare problems.

Journal of the Operational Research Society (2011) 62, 1431-1451. doi:10.1057/jors.2010.20

Published online 13 October 2010

Keywords: simulation; OR in health; research issues; research trends

\section{Introduction}

Healthcare needs grow and healthcare services become larger, more complex and costly (Eveborn et al, 2006; Wand, 2009). Moreover, the intrinsic uncertainty of healthcare demands and outcomes dictates that healthcare policy and management should be based on the evidence of its potential to tackle these stochastic problems. It seems apparent that computer modelling should be valuable in providing evidence and insights in coping with these systems. They can be used to forecast the outcome of a change in strategy or predict and evaluate the implications of the implementation of an alternative policy (Wierzbicki, 2007). The use of modelling in healthcare is not limited to the management of activities necessary to deliver care alone. It is also used for the study of several topics related to healthcare, for example, air pollution, pharmacokinetics and food poisoning. In this paper, we aim at profiling studies that have designed, applied, described, analysed or evaluated healthcare problems with the use of simulation modelling.

Computer simulation is a decision support technique that allows stakeholders to conduct experiments with models that represent real-world systems of interest (Pidd, 2004). It can be used as an alternative to 'learning by doing' or empirical

\footnotetext{
* Correspondence: K Katsaliaki, International Hellenic University, School of Economics \& Business Administration, 14th Klm ThessalonikiN.Moudania, 57001 Thermi, Thessaloniki, Greece.
}

research (Royston, 1999). Furthermore, simulation modelling gives stakeholders the opportunity to participate in model development and, hopefully, gain a deeper understanding of the problems they face. As a result, decision makers and stakeholders can gain a new perspective on the relationships between the given parameters, the level of systems' performance, the cost-effectiveness and its quality, or risk association.

In the field of Operations Management, simulation is recognised as the second most widely used technique after 'Modelling' (Amoako-Gympah and Meredith, 1989; Pannirselvam et al, 1999). Thus far, there have been a number of reviews in the literature on the applications of simulation to health. Fone et al (2003) have conducted a systematic review of the use and value of computer simulation methods in population health and healthcare. Eldabi et al (2007) reviewed the application of a diverse range of simulation techniques in healthcare settings. Brennan and Akehurst (2000) and Barrios et al (2008) considered the application of simulation in the economic evaluation of health technologies and health products as well as a proposed method for the evaluation of pharmacoecomonic models (Hay, 2004). Dexter (1999) includes a review of computer simulation and patient appointment systems. A number of reviews have focused on the applications of Discrete-Event Simulation (DES) in healthcare in general (England and Roberts, 1978), and more specifically in health clinics (Jun et al, 1999) and healthcare 
capacity management (Smith-Daniels et al, 1988). Hollocks (2006) gives a personal review of the use of Discrete Event Simulation in health among other fields.

However, most reviews limit themselves to either a single application area or/and a single simulation technique. Most of the current reviews lack the breadth of simulation techniques, the width of applications coverage and are published in outlets of different fields (eg medical, OR, health informatics journals, etc), thus potentially hampering the widespread reference and use of such studies.

Hence, the purpose of this review is to fill these gaps and categorise and synthesise academic literature pertaining to the use of computer simulation in health problems (a) over a number of unrelated publishing outlets, (b) with a broader scope of simulation techniques and (c) in a variety of health applications. This would, in turn, help in ascertaining the current development in the field of healthcare simulation.

In light of the above, by sampling publications pertaining to the application of simulation in the healthcare domain, we hope to realise the following objectives: (1) to classify publications according to the simulation methods they employ; (2) to determine the healthcare problems often investigated by these methods and to analyse their trends; (3) to identify the impact of published simulation research in the healthcare context; (4) to monitor results' demonstration and implementation; (5) to identify funding sources for healthcare simulation studies; (6) to identify software associated with the studies and show their frequency of use. In order to achieve these objectives, we have conducted a review of 251 articles published during the period 1970-2007. The main objective of this review is to offer a broad and extensive picture of the role of simulation techniques in healthcare. To the best of our knowledge, objectives (1) and (2) have not been previously investigated in a single study for all four selected simulation techniques in the health sector, and objectives (3) to (6) have not been presented in a published source-with the exception of England and Roberts (1978) who presented similar results for Discrete Event Simulation and System Dynamics over 30 years ago. It is hoped that the findings of our analysis will be beneficial to the community of simulation and healthrelated academics and practitioners.

The remainder of this paper is structured as follows. The next section ('Simulation modelling') provides a discussion of the different simulation methods selected for this study. The methodology employed for the research is explained under the 'Research methodology' section. The section on 'Research paradigm' categorises the applications of simulation under various simulation techniques and healthcare problems - this fulfils objectives (1) and (2). This is followed by the 'Research impact' section (fulfils objective 3 ) that identifies some important papers that have been reviewed in our study and measures their impact through a citation-based analysis. The section on 'Results implementation, funding sources and analysis of simulation software' presents statistics pertaining to these variables, and thereby fulfils objectives (4), (5) and (6). The penultimate section presents a 'Discussion' of the findings of this study, and the paper concludes with 'Conclusions and further reflections' that outline the limitations of our approach and reflect on the contribution of this work.

\section{Simulation modelling}

The simulation modelling techniques that were found appropriate for the purposes of this study are Monte Carlo Simulation (MCS), Discrete-Event Simulation (DES), System Dynamics (SD) and Agent-Based Simulation (ABS). Journal papers included in this study have been selected based on the criteria that the papers report on the use of one or more of these simulation techniques in the healthcare settings. The choice of simulation techniques was made through interaction with experts in this area but was also backed by the review of Jahangirian et al (2009) of simulation in business and manufacturing. The latter identifies the following simulation techniques: DES, SD, ABS, MCS, Intelligent Simulation, Traffic Simulation, Distributed Simulation, Simulation Gaming, Petri-Nets and Virtual Simulation, excluding simulation for physical design. According to this study, the first five techniques were the most commonly presented/used in the selected papers for that review. Initially in our study, we also considered papers that reported on the use of Intelligent Simulation and Parallel \& Distributed Simulation. However, these categories were later dropped owing to the fact that only a few relevant papers pertaining to the aforementioned categories were found in our sample study (one or two for each category). Moreover, our choice of simulation techniques is further supported by the study conducted by Fone et al (2003), wherein DES, SD and MCS are discussed as popular simulation techniques in healthcare. Those who wish to have an introduction to the aforementioned techniques can refer to Rubinstein (1981) for MCS, Robinson (1994) for DES, and Sterman (2001) for SD. ABS is the most recent of the four simulation methods used since the mid-1990s. A brief description of $\mathrm{ABS}$ is provided below.

ABS is a computational technique for modelling the actions and interactions of autonomous individuals (agents) in a network. The objective here is to assess the effects of these agents on the system as a whole (and 'not to' assess the effect of individual agents on the system). ABS is particularly appealing for modelling scenarios in which the consequences on the collective level are not obvious even when the assumptions on the individual level are very simple. This is so because ABS has the capability of generating complex properties emerging from the network of interactions among the agents, although the in-built rules of the individual agents' behaviour are quite simple.

\section{Research methodology}

In this paper, we have conducted a review of literature in healthcare simulation. Our review method has been influenced 


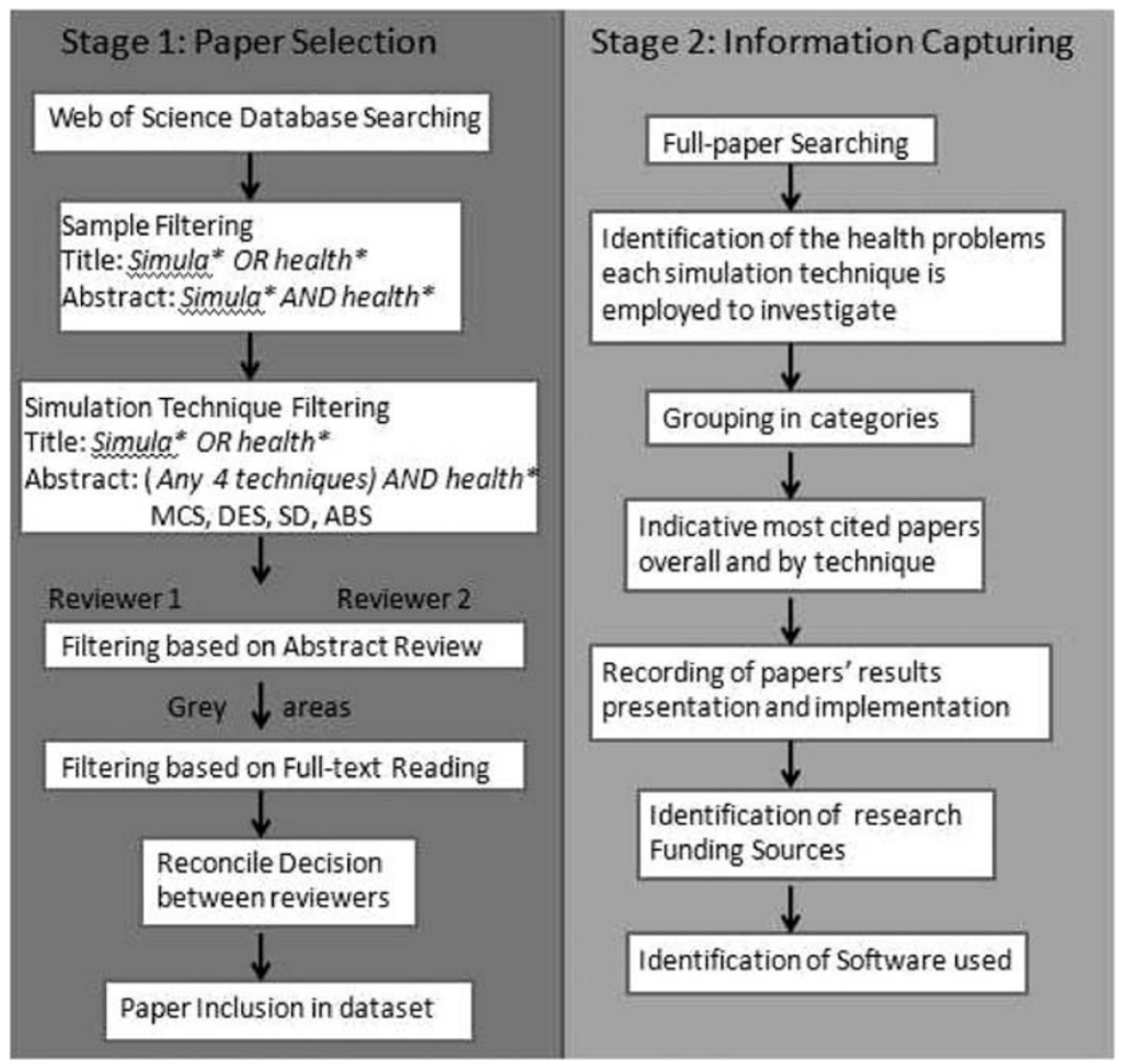

Figure 1 The literature profiling methodology.

by the systematic literature review approach adopted by Eddama and Coast (2008), wherein (a) databases such as ISI Web of Science ${ }^{\circledR}$ and MedLine ${ }^{\circledR}$ were searched using a combination of search terms, (b) papers were screened by reading article titles and abstracts and in accordance to some inclusion criteria, and (c) the contents of the papers selected in the earlier stage were reviewed. Our literature profiling methodology consists of two stages and is illustrated in Figure 1. Stage 1 is the 'Paper Selection' stage and it describes the methodology used for the purpose of selecting papers for inclusion in this study. Stage 2 is the 'Information Capturing' stage and it identifies the information that is captured from papers that have been included in the study; the latter is analysed in the subsequent sections of this paper. Both the stages of our methodology are further described below.

The papers selected for this study were identified from the Web of Science ${ }^{\circledR}$ database The Web of Science ${ }^{\circledR}$ is one of the largest databases of quality academic journals and provides access to bibliographic information pertaining to research articles published from 1970 onwards. It indexes approximately 8500 high impact research journals from all around the world spread across approximately 200 different disciplines. Our aim was to identify publications with the highest credibility and thus we looked only at journal articles having an impact factor (note: only journals with an impact factor are included in the ISI Web of Science ${ }^{\circledR}$ database).We do recognise, however, that other bibliographic databases could have also been looked at. But for the purpose of this research, we decided to include only the Web of Science ${ }^{\circledR}$ database since this study is not a systematic review but is a sample review of publications in healthcare simulation.

The Web of Science ${ }^{\circledR}$ has a user-friendly search engine that assists in the refinement of a search by allowing the user to incorporate specific search conditions. Our search strategy was driven by the simulation methodology used in the sought after papers. To identify articles that would be incorporated in our study's data set, the following criteria were used: inclusion of the words, 'simulat*' OR 'health' ${ }^{*}$ ' in the article's title and both of the words/phrases ('Monte SAME Carlo' AND 'health*') OR ('Discrete SAME Event*' AND 'health*') OR ('System* SAME Dynamics' AND 'health*') OR ('Agent SAME Based' AND 'health*') in the abstract or keywords of the published paper. The SAME operator returns records in which the terms separated by the operator appear in the same sentence. The use of the asterisk, '*' in the Boolean keywords combination, allowed for the inclusion of keyword derivatives in the search options. The search identified only articles and review papers written in the English language 
Table 1 Number of identified and selected papers

\begin{tabular}{lcrrr}
\hline Simulation methods & Identified papers & Percentage & Selected papers & Percentage \\
\hline Monte Carlo Simulation & 163 & 64.9 & 139 & 39.15 \\
Discrete-Event Simulation & 51 & 20.3 & 18.91 \\
System Dynamics & 31 & 12.4 & 17 & 2.46 \\
Agent-Based Simulation & 5 & 2.4 & 2 & 1.00 \\
Multiple Simulation & 0 & 0.0 & 5 & 2.49 \\
Sum & $\mathbf{2 5 1}$ & $\mathbf{1 0 0 . 0}$ & $\mathbf{2 0 1}$ \\
\hline
\end{tabular}

from 1970 until 2007 (inclusive). Results from this initial search strategy are shown in the second and third columns of Table 1. Sampling returned 251 papers in total.

The second step involved the screening of these papers. The two authors independently and critically reviewed all the abstracts of 251 papers' and read the full text when necessary. The appraisal was carried out based on certain inclusion criteria as follows: The selected papers should evidently demonstrate strong relation with the healthcare sector or have an impact on healthcare and use the chosen simulation method to describe, analyse or assess the situation. The paper should include at least one paragraph describing the applied simulation method that was used in the study. Thus, pure physics simulations and human systems simulations did not fulfil the inclusion criteria. The boundaries between healthrelated papers and non-health-related papers, were not always straightforward. In many papers the impact on human healthcare is provided by a less direct relationship. The reviewers took a flexible approach by including papers in which one could clearly relate the problem described with some kind of health impact. Each of the reviewers assessed all abstracts independently and compared the results were compared. In cases of discrepancies, the full text of the paper was examined and, after discussion between the reviewers, a decision was reached for the paper's inclusion or exclusion. This filtering resulted in a set of 201 relevant papers. The full text papers were collected via online or inter-library loan services.

The second stage concentrated on the content of the 201 papers in order to answer the six objectives of our study as identified in the introductory section. Of the selected papers, MCS seems by far to be $(69 \%)$ the most applied method dealing with health issues. It is followed by DES and SD. Finally, the method with the least number of papers is ABS-this is not a surprise since it is the most recently developed simulation technique. Table 1 (last two columns) lists the results of our screening. The last row of the table ('multiple simulation methods') identifies five papers that use or mention two or more simulation techniques. These ('multiple simulation methods') papers, for simplicity purposes, are described under the research paradigms of the four identified categories as explained in the next section. As this is a sample review, no inferences can be drawn from Table 1 as to the impact of each simulation method in healthcare. Nonetheless, we believe that the statistics below provide the readers with some understanding of the research trends in this area.

\section{Research paradigms}

The papers that have been included in our review are listed in separate tables [Tables 3-6]. These tables are presented in the relevant sub-sections associated with each simulation technique in question. Every paper has a unique identifier beginning with the initials of the simulation method under which it is categorised (MC, DES, SD, ABS) and is suffixed with a numerical value, for example MC1, MC20, etc. When many papers are listed in a row under the same category, the prefix is entered only at the beginning and is omitted from the rest of the papers for brevity (eg MC11, 27, 81). In the tables, these papers are presented in a descending date of publication order, and this, in turn, shows the research effort over these 37 years. Thus, small numbers correspond to the most recent publications and large numbers to the older ones. The Vancouver reference style is followed. Rather than including the references alphabetically at the end of the paper, we consider this scheme of collecting and tabulating all references pertaining to a particular simulation technique together at the end of each section as important because we feel that it improves the readability of the paper. These tables will also serve as a future reference/study list for the reader.

The papers pertaining to the different simulation techniques have been categorised under several general headings/categories. An overview of these categories is presented in Table 2 (objective 1). This is followed by a discussion of the categories under each of the four identified simulation techniques (objective 2). Some papers can be categorised under multiple headings and the decision to favour one classification category over the other was based on the relative importance attributed to specific simulation techniques in the discussion part of the paper.

\section{Monte Carlo Simulation}

MCS is the most predominantly used simulation technique of the four identified techniques. Of the 163 reviewed papers in MCS, we found 142 to be suitable for inclusion in our dataset (Table 3).

In the context of healthcare, MCS has generally been used for the following purposes: (a) To assess health risks 
Table 2 Categories and number of papers in healthcare simulation per simulation technique

(a) Health risk assessment (drug development-dose response, air-water-food-soil contamination)

(b) Prognostic and transmission models of health interventions (disease transmission stages, regression and robustness models)

(c) Cost-benefit analysis and policy evaluation of medical treatment and disease management (population-based screen-and-treat strategy)

(d) Miscellaneous (literature reviews and taxonomies, health surveys and service delivery)

DES

(a) Planning of healthcare services (hospitals, A \& E departments, Scheduling health staff-patient admissions/appointments-ambulances, bed and equipment capacity, health information systems, organ transplantation, locations of healthcare services and facilities design)

(b) Health economic models (cost of providing healthcare, alternative healthcare interventions, screening strategies, cost-effectiveness of ordering and distribution policies)

(c) Reviews and methodology papers (comparison and evaluation of modelling techniques)

(d) Contagious disease interventions (control the spread of diseases/epidemics, plan emergency clinics)

(a) Public health policy evaluation and economic models (harm reduction policies, treating strategies, long-term health impact, disease population dynamics, reconfiguration of health services, health insurance strategies)

(b) Modelling healthcare systems and infrastructure (Unscheduled care, A \& E demand pattern, resource deployment, parallel hospital processes, health infrastructure disruptions and disasters)

(c) Training (health policymakers-understanding the dynamics of diseases, students experimentation with pharmacological systems)

(d) Review

(Interactions of cancer hallmarks and therapies, health data confidentiality)

from exposure to certain elements and determine drug doseresponse portions; this is the most popular sub-category with 60 papers in our sample; (b) as the main approach to modelling used in economic evaluations in healthcare interventions when there is a need to increase the number of states in the model to overcome the homogeneity assumptions inherent in Markov models and decision trees (Barton et al, 2004) (18 papers); (c) to evaluate the cost-effectiveness of competing technologies or healthcare strategies that require the description of patient pathways over extended time horizons with 41 papers in this sub-category; and (d) for Miscellaneous taxonomies, literature review and feasibility studies with 23 papers altogether. Each of these four issues will now be looked at in greater depth.

Health risk assessment Numerous environmental and occupational studies have shown a link between the measures of public health and intake of contaminants, via different environmental media and exposure routes such as inhalation, skin and ingestion. Twenty-two studies focused on air pollution [MC3, 10, 20, 26, 29, 40, 43, 51, 55, 79, 88, 90, 97, 102, $114,124,126,132,133,135,136,140]$, nine on water pollution [MC21, 62, 76, 93, 95, 98, 103, 116, 127], 11 on food poisoning $[\mathrm{MC} 5,13,34,56,77,100,111,113,118,122$, 125] and three on soil contamination [MC119, 128, 142]. In such health risk assessments or epidemiological studies, the exact amount of a chemical or contaminant that an individual comes into contact with over a lifetime should ideally be estimated. However, for many obvious reasons this estimation is difficult. Simulation studies can fill in data gaps regarding historical exposures by generating these data using parametric functions, which are critical to improving the power of such studies. MCS is the method most commonly used for classical probabilistic risk assessments that uses mathematical or statistical models to estimate the frequency in which an event will occur. This technique is particularly useful when a large number of algorithms are required to address various multipathways of exposure to humans. The use of Monte Carlo analysis has reformed the practice of exposure assessment and has greatly enhanced the quality of the risk characterisation.

Moreover, 15 risk assessment studies focus on drug development and dose-response portion [MC4, 14, 17, 19, 31, 42, 47, 52, 53, 54, 67, 71, 80, 106, 137]. MCS can be used to determine the Probability of Target Attainment of pharmacodynamic indices by taking the inherent variation of different populations into account. In MCS, the model parameters are treated as stochastic or random variables, by using a probability density function for example, rather than fixed values. The aim of these studies is to establish a population pharmacokinetic model to study the parameters for the drug being administered through an intravenous escalating dosing regimen in healthy subjects, which could, in turn, be used for design of patient protocols with direct therapeutic benefit and maximal safety. These simulations are dependent on the assumptions in the model, including the types and number of subjects in the pharmacokinetic studies and the data used. Differences in pharmacokinetic parameters (for different patient populations) and/or data can lead to differences in 
Table 3 MCS papers included in the present study

\begin{tabular}{cl}
\hline S No. & MC paper \\
\hline 1 & $\begin{array}{l}\text { Piatt JH, Cosgriff M. Monte Carlo simulation of cerebrospinal fluid shunt failure and definition of instability among shunt- } \\
\text { treated patients with hydrocephalus. J. Neurosurg. 2007 DEC; 107(6): 474-478. }\end{array}$ \\
2 & $\begin{array}{l}\text { Mannan HR, Knuiman M, Hobbs M. A Markov simulation model for analyzing and forecasting the number of coronary artery } \\
\text { revascularization procedures in Western Australia. Ann. Epidemiol. 2007 DEC; 17(12): 964-975. }\end{array}$ \\
3 & $\begin{array}{l}\text { Lee D, Shaddick G. Time-varying coefficient models for the analysis of air pollution and health outcome data. Biometrics } 2007 \\
\text { DEC; 63(4): 1253-1261. }\end{array}$ \\
& $\begin{array}{l}\text { Fabre MA, Fuseau E, Ficheux H. Selection of dosing regimen with WST11 by Monte Carlo simulations, using PK data collected } \\
\text { after single IV administration in healthy subjects and population PK Modelling. J. Pharm. Sci. 2007 DEC; } 96(12): 3444-3456 .\end{array}$ \\
5 & $\begin{array}{l}\text { Antonijevic B, Matthys C, Sioen I, Bilau M, Van Camp J, Willems JL, et al. Simulated impact of a fish based shift in the } \\
\text { population n-3 fatty acids intake on exposure to dioxins and dioxin-like compounds. Food and Chemical Toxicology 2007 }\end{array}$
\end{tabular}
NOV; 45(11): 2279-2286.

6 Schadlich PK, Schmidt-Lucke C, Huppertz E, Lehmacher W, Nixdorff U, Stellbrink C, et al. Economic evaluation of Enoxaparin for anticoagulation in early Cardioversion of persisting nonvalvular atrial fibrillation: A statutory health insurance perspective from Germany. American Journal of Cardiovascular Drugs 2007; 7(3): 199-217.

7 Huang ES, Zhang Q, Brown SES, Drum ML, Meltzer DO, Chin MH. The cost-effectiveness of improving diabetes care in US Federally qualified community health centers. Health Serv. Res. 2007 DEC; 42(6): 2174-2193.

8 O'Hagan A, Stevenson M, Madan J. Monte Carlo probabilistic sensitivity analysis for patient level simulation models: Efficient estimation of mean and variance using ANOVA. Health Econ. 2007 OCT; 16(10): 1009-1023.

9 Schwenkglenks M, Lippuner K. Simulation-based cost-utility analysis of population screening-based alendronate use in Switzerland. Osteoporosis Int. 2007 NOV; 18(11): 1481-1491.

10 Djohan D, Yu J, Connell D, Christensen E. Health risk assessment of chlorobenzenes in the air of residential houses using probabilistic techniques. Journal of Toxicology and Environmental Health-Part A-Current Issues 2007; 70(19): 1594-1603.

11 Peeler EJ, Murray AG, Thebault A, Brun E, Giovaninni A, Thrush MA. The application of risk analysis in aquatic animal health management. Prev. Vet. Med. 2007 SEP 14; 81(1-3): 3-20.

12 Gerkens S, Nechelput M, Annemans L, Peraux B, Mouchart M, Beguin C, et al. A health economic model to assess the costeffectiveness of PEG IFN alpha-2a and ribavirin in patients with mild chronic hepatitis C. J. Viral Hepat. 2007 AUG; 14(8): 523-536.

13 Straver JM, Janssen AFW, Linnemann AR, van Boekel MAJS, Beumer RR, Zwietering MH. Number of Salmonella on chicken breast filet at retail level and its implications for public health risk. J. Food Prot. 2007 SEP; 70(9): 2045-2055.

14 Vinks AA, van Rossem RN, Mathot RAA, Heijerman HGM, Mouton JW. Pharmacokinetics of aztreonam in healthysubjects and patients with cystic fibrosis and evaluation of dose-exposure relationships using Monte Carlo simulation. Antimicrob. Agents Chemother. 2007 SEP; 51(9): 3049-3055.

15 Gerkens S, Nechelput M, Annemans L, Peraux B, Beguin C, Horsmans Y. A health economic model to assess the costeffectiveness of pegylated interferon alpha-2a and ribavirin in patients with moderate chronic hepatitis $\mathrm{C}$ and persistently normal alanine aminotransferase levels. Acta Gastroenterol. Belg. 2007 APR-JUN; 70(2): 177-187.

16 Santori G, Valente R, Andorno E, Ghirelli R, Valente U. Application of a Bayesian simulation model to a database for split liver transplantation on two adult recipients in the environment of WinBUGS (Bayesian inference Using Gibbs Sampling). Transplant. Proc. 2007 JUL-AUG; 39(6): 1918-1920.

17 Burgess DS, Hall RG. Simulated comparison of the pharmacodynamics of ciprofloxacin and levofloxacin against Pseudomonas aeruginosa using pharmacokinetic data from healthy volunteers and 2002 minimum inhibitory concentration data. Clin. Ther. 2007 JUL; 29(7): 1421-1427.

18 Lawson AB, Williams FLR, Liu Y. Some simple tests for spatial effects around putative sources of health risk. Biometrical Journal 2007 AUG; 49(4): 493-504.

19 Bulitta JB, Dufful SB, Kinzig-Schippers M, Holzgrabe U, Stephan U, Drusano GL, et al. Systematic comparison of the population pharmacokinetics and pharmacodynamics of piperacillin in cystic fibrosis patients and healthy volunteers. Antimicrob. Agents Chemother. 2007 JUL; 51(7): 2497-2507.

20 Lonati G, Cernuschi S, Giugliano M, Grosso M. Health risk analysis of PCDD. Chemosphere 2007 APR; 67(9): S334-S343.

21 Mara DD, Sleigh PA, Blumenthal UJ, Carr RM. Health risks in wastewater irrigation: Comparing estimates from quantitative microbial risk analyses and epidemiological studies. Journal of Water and Health 2007 MAR; 5(1): 39-50.

22 Sparrow JM. Monte-Carlo simulation of random clustering of endophthalmitis following cataract surgery. Eye 2007 FEB; 21(2): 209-213.

23 Kahn JM, Kramer AA, Rubenfeld GD. Transferring critically ill patients out of hospital improves the standardized mortality ratio-A simulation study. Chest 2007 JAN; 131(1): 68-75.

24 Lamotte M, Annemans L, Kawalec P, Zoellner Y. A multi-country health-economic evaluation of highly concentrated n-3 polyunsaturated fatty acids in the secondary prevention after myocardial infarction. Herz 2006 DEC; 31: 74-82.

25 Roze S, Liens D, Palmer A, Berger W, Tucker D, Renaudin C. A health economic model to determine the long-term costs and clinical outcomes of raising low HDL-cholesterol in the prevention of coronary heart disease. Curr. Med. Res. Opin. 2006 DEC; 22(12): 2549-2556.

26 Mestl HES, Aunan K, Seip HM. Potential health benefit of reducing household solid fuel use in Shanxi province, China. Sci. Total Environ. 2006 DEC 15; 372(1): 120-132.

27 Nieuwenhuijsen M, Paustenbach D, Duarte-Davidson R. New developments in exposure assessment: The impact on the practice of health risk assessment and epidemiological studies. Environ. Int. 2006 DEC; 32(8): 996-1009. 
Table 3 (Continued)

S No. MC paper

28 Deb P, Munkin MK, Trivedi PK. Private insurance, selection, and health care use: A Bayesian analysis of a Roy-type model. Journal of Business \& Economic Statistics 2006 OCT; 24(4): 403-415.

29 Mudra R, Nadler A, Keller E, Niederer P. Analysis of near-infraredspectroscopy and indocyanine green dye dilution with Monte Carlo simulation of light propagation in the adult brain. J. Biomed. Opt. 2006 JUL-AUG; 11(4): 044009.

30 Feveile H, Mikkelsen KL, Hannerz H, Olsen O. Quantifying inequality in health in the absence of a natural reference group. Sci. Total Environ. 2006 AUG 15; 367(1): 112-122.

31 Sprandel KA, Drusano GL, Hecht DW, Rotschafer JC, Danziger LH, Rodvold KA. Population pharmacokinetic Modelling and Monte Carlo simulation of varying doses of intravenous metronidazole. Diagn. Microbiol. Infect. Dis. 2006 AUG; 55(4): 303-309.

32 Kleinschmidt I, Ramkissoon A, Morris N, Mabude Z, Curtis B, Beksinska M. Mapping indicators of sexually transmitted infection services in the South African public health sector. Tropical Medicine \& International Health 2006 JUL; 11(7): 1047-1057.

33 Flampouri S, Jiang SB, Sharp GC, Wolfgang J, Patel AA, Choi NC. Estimation of the delivered patient dose in lung IMRT treatment based on deformable registration of 4D-CT data and Monte Carlo simulations. Phys. Med. Biol. 2006 JUN 7; 51(11): 2763-2779.

34 Chien LC, Han BC, Hsu CS, Jiang CB, You HJ, Shieh MJ, et al. Analysis of the health risk of exposure to breast milk mercury in infants in Taiwan. Chemosphere $2006 \mathrm{JUN}$; 64(1): 79-85.

35 Riedel O. Unisex tariffs in health insurance. Geneva Papers on Risk and Insurance-Issues and Practice 2006 APR; $31(2)$ : 233-244.

36 Langenderfer JE, Carpenter JE, Johnson ME, An KN, Hughes RE. A probabilistic model of glenohumeral external rotation strength for healthy normals and rotator cuff tear cases. Ann. Biomed. Eng. 2006 MAR; 34(3): 465-476.

37 Van Howe RS, Kusnier LP. Diagnosis and management of pharyngitis in a pediatric population based on cost-effectiveness and projected health outcomes. Pediatrics 2006 MAR; 117(3): 609-619.

38 Schoen EJ, Colby CJ, To TT. Cost analysis of neonatal circumcision in a large health maintenance organization. J. Urol. 2006 MAR; 175(3): 1111-1115.

39 Veerman JL, Barendregt JJ, Mackenbach JP. The European Common Agricultural Policy on fruits and vegetables: exploring potential health gain from reform. Eur. J. Public Health 2006 FEB; 16(1): 31-35.

40 Hincks TK, Aspinall WP, Baxter PJ, Searl A, Sparks RSJ, Woo G. Long term exposure to respirable volcanic ash on Montserrat: a time series simulation. Bulletin of Volcanology 2006 JAN; 68(3): 266-284.

41 Whited JD, Datta SK, Aiello LM, Aiello LP, Cavallerano JD, Conlin PR, et al. A modeled economic analysis of a digital teleophthalmology system as used by three federal healthcare agencies for detecting proliferative diabetic retinopathy. Telemedicine Journal and E-Health 2005 DEC; 11(6): 641-651.

42 Gudowska I, Sobolevsky N. Simulation of secondary particle production and absorbed dose to tissue in light ion beams. Radiat. Prot. Dosimet. 2005 DEC 20; 116(1-4): 301-306.

43 Chen Y, Bielajew AF, Litzenberg DW, Moran JM, Becchetti FD. Magnetic confinement of electron and photon radiotherapy dose: A Monte Carlo simulation with a nonuniform longitudinal magnetic field. Med. Phys. 2005 DEC; 32(12): 3810-3818.

44 Postma MJ, Jansema P, Scheijbeler HWKFH, van Genugten MLL. Scenarios on costs and savings of influenza treatment and prevention for Dutch healthy working adults. Vaccine 2005 NOV 16; 23(46-47): 5365-5371.

45 Zhou H, IsamanDJM, Messinger S, Brown MB, Klein R, Brandle M, et al. A computer simulation model of diabetes progression, quality of life, and cost. Diabetes Care 2005 DEC; 28(12): 2856-2863.

46 Zarkin GA, Dunlap LJ, Hicks KA, Mamo D. Benefits and costs of methadone treatment: results from a lifetime simulation model. Health Econ. 2005 NOV; 14(11): 1133-1150.

47 Wei HJ, Xing D, Wu GY, Gu HM, Lu FJ, Jin Y, et al. Differences in optical properties between healthy and pathological human colon tissues using a Ti: sapphire laser: an in vitro study using the Monte Carlo inversion technique. J. Biomed. Opt. 2005 JUL-AUG; 10(4): 044022

48 Jackson BR, Thomas A, Carroll KC, Adler FR, Samore MH. Use of strain typing data to estimate bacterial transmission rates in healthcare settings. Infection Control and Hospital Epidemiology 2005 JUL; 26(7): 638-645.

49 Xu M, Garbuz DS, Kuramoto L, Sobolev B. Classifying health-related quality of life outcomes of total hip arthroplasty. BMC Musculoskeletal Disorders 2005 SEP 6; 6: 48.

50 Roze S, Valentine WJ, Zakrzewska KE, Palmer AJ. Health-economic comparison of continuous subcutaneous insulin infusion with multiple daily injection for the treatment of Type 1 diabetes in the UK. Diabetic Med. 2005 SEP; 22(9): 1239-1245.

51 Yang Y, Tao S, Wong PK, Hu JY, Guo M, Cao HY, et al. Human exposure and health risk of alpha-, beta-, gamma- and delta-hexachlorocyclohexane in Tianjin, China. Chemosphere 2005 AUG; 60(6): 753-761.

52 Mouton JW, Punt N, Vinks AA. A retrospective analysis using Monte Carlo simulation to evaluate recommended ceftazidime dosing regimens in healthy volunteers, patients with cystic fibrosis, and patients in the intensive care unit. Clin. Ther. 2005 JUN; 27(6): 762-772.

53 Kuti JL, Horowitz S, Nightingale CH, Nicolau DP. Comparison of pharmacodynamic target attainment between healthy subjects and patients for ceftazidime and meropenem. Pharmacotherapy 2005 JUL; 25(7): 935-941.

54 Krueger WA, Bulitta J, Kinzig-Schippers M, Landersdorfer C, Holzgrabe U, Naber KG, et al. Evaluation by Monte Carlo simulation of the pharmacokinetics of two doses of meropenem administered intermittently or as a continuous infusion in healthy volunteers. Antimicrob. Agents Chemother. 2005 MAY; 49(5): 1881-1889.

55 Gower SK, McColl S. Development of the PEARLS model and use of Monte Carlo simulation to predict internal exposure to PM2.5 in Toronto. Risk Analysis 2005 APR; 25(2): 301-315. 
Table 3 (Continued)

S No. MC paper

56 Shih TW, Chou CC, Morley RS. Monte Carlo simulation of animal-product violations incurred by air passengers at an international airport in Taiwan. Prev. Vet. Med. 2005 MAY 10; 68(2-4): 115-122.

57 Russek-Cohen E, Martinez MN, Nevius AB. A SAS/IML program for simulating pharmacokinetic data. Comput. Methods Programs Biomed. 2005 APR; 78(1): 39-60.

58 Shechter SM, Bryce CL, Alagoz O, Kreke JE, Stahl JE, Schaefer AJ, et al. A clinically based discrete-event simulation of end-stage liver disease and the organ allocation process. Medical Decision Making 2005 MAR-APR; 25(2): $199-209$.

59 Patten SB. An analysis of data from two general health surveys found that increased incidence and duration contributed to elevated prevalence of major depression in persons with chronic medical conditions. J. Clin. Epidemiol. 2005 FEB; 58(2): 184-189.

60 Rolka H, Bracy D, Russel C, Fram D, Ball R. Using simulationto assess the sensitivity and specificity of a signal detection tool for multidimensional public health surveillance data. Stat. Med. 2005 FEB 28; 24(4): 551-562.

61 Holm MV, Gyldmark M, Hansen EH. Pharmacoeconomic assessment of oseltamivir in treating influenza-the case of otherwise healthy Danish adolescents and adults. Pharmacy World \& Science 2004 DEC; 26(6): 339-345.

62 Chowdhury S, Husain T, Veitch B, Bose N, Sadiq R. Human health risk assessment of naturally occurring radioactive materials in produced water-A case study. Hum. Ecol. Risk Assess. 2004 DEC; 10(6): 1155-1171.

63 Gagnon YM, Levy AR, Iloeje UH, Briggs AH. Treatment costs in Canada of health conditions resulting from chronic hepatitis B infection. J. Clin. Epidemiol. 2004 AUG; 38(S10): S179-86.

64 Lynd LD, O'Brien BJ. Advances in risk-benefit evaluation using probabilistic simulation methods: an application to the prophylaxis of deep vein thrombosis. J. Clin. Epidemiol. 2004 AUG; 57(8): 795-803.

65 Palmer AJ, Rodby RA. Health economics studies assessing irbesartan use in patients with hypertension, type 2 diabetes, and microalbuminuria. Kidney Int. 2004 NOV; 66: S118-S120.

66 Jochmann M, Leon-Gonzalez R. Estimating the demand for health care with panel data: a semiparametric Bayesian approach. Health Econ. 2004 OCT; 13(10): 1003-1014.

67 Duggan DM. Improved radial dose function estimation using current version MCNP Monte-Carlo simulation: Model 6711 and ISC3500(125)I brachytherapy sources. Applied Radiation and Isotopes 2004 DEC; 61(6): 1443-1450.

68 van Alem AP, Dijkgraaf MGW, Tijssen JGP, Koster RW. Health system costs of out-of-hospital cardiac arrest in relation to time to shock. Circulation 2004 OCT 5; 110(14): 1967-1973.

69 Nuijten MJC. Incorporation of statistical uncertainty in health economic modelling studies using second-order Monte Carlo simulations. Pharmacoeconomics 2004; 22(12): 759-769.

70 Haby MM, Carter R, Mihalopoulos C, Magnus A, Sanderson K, Andrews G, et al. Assessing cost-effectiveness-Mental health: introduction to the study and methods. Aust. N. Z. J. Psychiatry 2004 AUG; 38(8): 569-578.

71 Bonate PL, Floret S, Bentzen C. Population pharmacokinetics of APOMINE (TM): A meta-analysis in cancer patients and healthy males. Br. J. Clin. Pharmacol. 2004 AUG; 58(2): 142-155.

72 Ong MK, Glantz SA. Cardiovascular health and economic effects of smoke-free workplaces. Am. J. Med. 2004 JUL 1; 117(1): 32-38.

73 Sonnenberg FA, Burkman RT, Hagerty CG, Speroff L, Speroff T. Costs and net health effects of contraceptive methods. Contraception 2004 JUN; 69(6): 447-459.

74 Borsuk ME. Predictive assessment of fish health and fish kills in the Neuse River Estuary using elicited expert judgment. Hum. Ecol. Risk Assess. 2004 APR; 10(2): 415-434.

75 Stott SL, Irimia D, Karlsson JM. Parametric analysis of intercellular ice propagation during cryosurgery, simulated using Monte Carlo techniques. Technology in Cancer Research \& Treatment 2004 APR; 3(2): 113-123.

76 Pouillot R, Beaudeau P, Denis JB, Derouin F, AFSSA Cryptosporidium Study Grp. A quantitative risk assessment of waterborne cryptosporidiosis in France using second-order Monte Carlo simulation. Risk Analysis 2004 FEB; 24(1): 1-17.

77 Cox LA, Popken DA. Quantifying human health risks from virginiamycin used inchickens. Risk Analysis 2004 FEB; 24(1): 271-288.

78 Stuart B, Singhal PK, Magder LS, Zuckerman IH. How robust are health plan quality indicators to data loss? A Monte Carlo simulation study of pediatric asthma treatment. Health Serv. Res. 2003 DEC; 38(6): 1547-1561.

79 Sanhueza PA, Reed GD, Davis WT, Miller TL. An environmental decision-making tool for evaluating ground-level ozone-related health effects. J. Air Waste Manage. Assoc. 2003 DEC; 53(12): 1448-1459.

80 Kuti JL, Dandekar PK, Nightingale CH, Nicolau DP. Use of Monte Carlo simulation to design an optimized pharmacodynamic dosing strategy for meropenem. J. Clin. Pharmacol. 2003 OCT; 43(10): 1116-1123.

81 Rushton G. Public health, GIS, and spatial analytic tools. Annu. Rev. Public Health 2003; 24: 43-56.

82 Romeu A, Balasch J, Balda JAR, Barri PN, Daya S, Auray JP, et al. Cost-effectiveness of recombinant versus urinary folliclestimulating hormone in assisted reproduction techniques in the Spanish public health care system. J. Assist. Reprod. Genet. 2003 AUG; 20(8): 294-300.

83 Nichol KL, Mallon KP, Mendelman PM. Cost benefit of influenza vaccination in healthy, working adults: an economic analysis based on the results of a clinical trial of trivalent live attenuated influenza virus vaccine. Vaccine 2003 MAY 16; 21(17-18): 2207-2217.

84 Munkin MK, Trivedi PK. Bayesian analysis of a self-selection model with multiple outcomes using simulation-based estimation: an application to the demand for healthcare. J. Econ. 2003 JUN; 114(2): 197-220.

85 Hahl J, Simell T, Kupila A, Keskinen P, Knip M, Ilonen J, et al. A simulation model for estimating direct costs of type 1 diabetes prevention. Pharmacoeconomics 2003; 21(5): 295-303. 
Table 3 (Continued)

\begin{tabular}{cl}
\hline S No. & MC paper \\
\hline 86 & $\begin{array}{l}\text { Carlsson F, Martinsson P. Design techniques for stated preference methods in health economics. Health Econ. 2003 APR; 12(4): } \\
\text { 281-294. }\end{array}$ \\
87 & $\begin{array}{l}\text { O'Brien BJ, Goeree R, Blackhouse G, Smieja M, Loeb M. Oseltarnivir for treatment of influenza in healthy adults: Pooled } \\
\text { trial evidence and cost-effectiveness model for Canada. Value in Health } 2003 \text { MAR-APR; } 6(2): 116-125 .\end{array}$ \\
88 & $\begin{array}{l}\text { Chabaud S, Girard P, Nony P, Boissel JP, THERMOS Grp. Clinical trial simulation using therapeutic effect Modelling: } \\
\text { Application to ivabradine efficacy in patients with angina pectoris. Journal of Pharmacokinetics and Pharmacodynamics 2002 } \\
\text { AUG; 29(4): 339-363. }\end{array}$
\end{tabular}

89 Vichiendilokkul A. Breaking out of the silo: One health system's experience. American Journal of Health-System Pharmacy 2002 OCT 15; 59: S15-S17.

90 Dobrev ID, Andersen ME, Yang RSH. In silico toxicology: Simulating interaction thresholds for human exposure to mixtures of trichloroethylene, tetrachloroethylene, and 1,1,1-trichloroethane. Environ. Health Perspect. 2002 OCT; 110(10): 1031-1039.

91 McCleese DL, LaPuma PT. Using Monte Carlo simulation in life cycle assessment for electric and internal combustion vehicles. International Journal of Life Cycle Assessment 2002; 7(4): 230-236.

92 Nichol KL, Goodman M. Cost effectiveness of influenza vaccination for healthy persons between ages 65 and 74 years. Vaccine 2002 MAY 15; 20: S21-S24.

93 Sadiq R, Husain T, Kar S. Chloroform associated health risk assessment using bootstrapping: A case study for limited drinking water samples. Water Air and Soil Pollution 2002 JUL; 138(1-4): 123-140.

94 Richter A, Hauber B, Simpson K, Mauskopf JA, YinDP. A Monte Carlo simulation for modelling outcomes of AIDS treatment regimens. Pharmacoeconomics 2002; 20(4): 215-224.

95 Lee LJH, Chan CC, Chung CW, Ma YC, Wang GS, Wang JD. Health risk assessment on residents exposed to chlorinated hydrocarbons contaminated in groundwater of a hazardous waste site. Journal of Toxicology and Environmental Health-Part A 2002 FEB; 65(3-4): 219-235.

96 Emery S, Ake CF, Navarro AM, Kaplan RM. Simulated effect of tobacco tax variation on Latino health in California. Am. $J$. Prev. Med. 2001 NOV; 21(4): 278-283.

97 Chan TL, Dong G, Cheung CS, Leung CW, Wong CP, Hung WT. Monte Carlo simulation of nitrogen oxides dispersion from a vehicular exhaust plume and its sensitivity studies. Atmos. Environ. 2001 DEC; 35(35): 6117-6127.

98 Chen Z, Huang GH, Chakma A. Simulation and assessment of subsurface contamination caused by spill and leakage of petroleum products-A multiphase, multicomponent modelling approach. J Can Pet Technol 2001 SEP; 40(9): 43-49.

99 Pereira A. Health and economic consequences of HCV lookback. Transfusion 2001 JUN; 41(6): 832-839.

100 Wilson ND, Price PS, Paustenbach DJ. An event-by-event probabilistic methodology for assessing the health risks of persistent chemicals in fish: A case study at the Palos Verdes Shelf. Journal of Toxicology and Environmental Health-Part A 2001 APR 20; 62(8): 595-642.

101 Nichol KL. Cost-benefit analysis of a strategy to vaccinate healthy working adults against influenza. Arch. Intern. Med. 2001 MAR 12; 161(5): 749-759.

102 Thornburg J, Ensor DS, Rodes CE, Lawless PA, Sparks LE, Mosley RB. Penetration of particles into buildings and associated physical factors. Part I: Model development and computer simulations. Aerosol Science and Technology 2001 MAR; 34(3): 284-296.

103 Warila J, Batterman S, Passino-Reader DR. A probabilistic model for silver bioaccumulation in aquatic systems and assessment of human health risks. Environmental Toxicology and Chemistry 2001 FEB; 20(2): 432-441.

104 Silcocks PBS, Jenner DA, Reza R. Life expectancy as a summary of mortality in a population: statistical considerations and suitability for use by health authorities. J. Epidemiol. Community Health 2001 JAN; 55(1): 38-43.

105 Austin PC, Escobar M, Kopec JA. The use of the Tobit model for analyzing measures of health status. Quality of Life Research 2000; 9(8): 901-910.

106 Ambrose PG, Grasela DM. The use of Monte Carlo simulation to examine pharmacodynamic variance of drugs: fluoroquinolone pharmacodynamics against Streptococcus pneumoniae. Diagn. Microbiol. Infect. Dis. 2000 NOV; 38(3): 151-157.

107 Draper D, Fouskakis D. A case study of stochastic optimization in health policy: Problem formulation and preliminary results. J. Global Optimiz. 2000 DEC; 18(4): 399-416.

108 Pereira A, Sanz C. A model of the health and economic impact of posttransfusion hepatitis C: application to cost-effectiveness analysis of further expansion of HCV screening protocols. Transfusion 2000 OCT; 40(10): 1182-1191.

109 Scheid DC, Hamm RM, Stevens KW. Cost effectiveness of human immunodeficiency virus postexposure prophylaxis for healthcare workers. Pharmacoeconomics 2000 OCT; 18(4): 355-368.

110 Taibi A, Royle GJ, Speller RD. A Monte Carlo simulation study to investigate the potential of diffraction enhanced breast imaging.IEEE Trans. Nucl. Sci. 2000 AUG; 47(4): 1581-1586.

111 Ostergaard S, Sorensen JT, Kristensen AR. A stochastic model simulating the feeding-health-production complex in a dairy herd. J. Dairy Sci. 2000 APR; 83(4): 721-733.

112 Veugelers PJ, Kim AL, Guernsey JR. Inequalities in health. Analytic approaches based on life expectancy and suitable for small area comparisons. J. Epidemiol. Community Health 2000 MAY; 54(5): 375-380.

113 Gates P, Johansson K, Danell B. 'Quasi-REML' correlation estimates between production and health traits in the presence of selection and confounding: A simulation study. J. Anim. Sci. 1999 MAR; 77(3): 558-568.

114 Boudet C, Zmirou D, Laffond M, Balducci F, Benoit-Guyod JL. Health risk assessment of a modern municipal waste incinerator. Risk Analysis 1999 DEC; 19(6): 1215-1222. 
Table 3 (Continued)

S No. MC paper

115 Briggs AH, Mooney CZ, Wonderling DE. Constructing confidence intervals for cost-effectiveness ratios: An evaluation of parametric and non-parametric techniques using Monte Carlo simulation. Stat. Med. 1999 DEC 15; 18(23): 3245-3262.

116 Olivieri A, Eisenberg D, Soller J, Eisenberg J, Cooper R, Tchobanoglous G, et al. Estimation of pathogen removal in an advanced water treatment facility using Monte Carlo simulation. Water Science and Technology 1999; 40(4-5): 223-233.

117 Zmirou D, Deloraine A, Balducci F, Boudet C, Dechenaux J. Health effects costs of particulate air pollution. Journal of Occupational and Environmental Medicine 1999 OCT; 41(10): 847-856.

118 Jordan D, McEwen SA, Lammerding AM, McNab WB, Wilson JB. A simulation model for studying the role of pre-slaughter factors on the exposure of beef carcasses to human microbial hazards. Prev. Vet. Med. 1999 JUN 29; 41(1): 37-54.

119 Hamed MM. Probabilistic sensitivity analysis of public health risk assessment from contaminated soil. J. Soil Contam. 1999 MAY; 8(3): 285-306.

120 Crijns H, Casparie AF, Hendrikse F. Continuous computer simulation analysis of the cost-effectiveness of screening and treating diabetic retinopathy. Int. J. Technol. Assess. Health Care 1999 WIN; 15(1): 198-206.

121 Sumner W, Truszczynski M, Marek VW. Simulating patients with parallel health state networks. Journal of the American Medical Informatics Association 1998: 438-442.

122 Cassin MH, Paoli GM, Lammerding AM. Simulation Modelling for microbial risk assessment. J. Food Prot. 1998 NOV; 61(11): $1560-1566$.

123 Jacobson SH, Morrice DJ. A mathematical model for assessing the temporal association between health disorders and medical treatments. Journal of Statistical Planning and Inference 1998 AUG 1; 71(1-2): 209-228.

124 Katsumata PT, Kastenberg WE. On the assessment of the maximally exposed individual at superfund sites using Monte Carlo simulations. Journal of Environmental Science and Health Part A-Toxic/hazardous Substances \& Environmental Engineering 1998; 33(6): 951-985.

125 Marseguerra M, Zio E. Contaminant transport in bidimensional porous media via biased Monte Carlo simulation. Ann. Nucl. Energy 1998 NOV; 25(16): 1301-1316.

126 Allan M, Richardson GM. Probability density functions describing 24-hour inhalation rates for use in human health risk assessments. Hum. Ecol. Risk Assess. 1998 APR; 4(2): 379-408.

127 Piver WT, Duval LA, Schreifer JA. Evaluating health risks from ground-water contaminants.Journal of Environmental Engineering-ASCE 1998 MAY; 124(5): 475-478.

128 James AL, Oldenburg CM. Linear and Monte Carlo uncertainty analysis for subsurface contaminant transport simulation. Water Resour. Res. 1997 NOV; 33(11): 2495-2508.

129 Hamed MM. First-order reliability analysis of public health risk assessment. Risk Analysis 1997 APR; 17(2): 177-185.

130 Burmaster DE, Wilson AM. An introduction to second-order random variables in human health risk assessments. Hum. Ecol. Risk Assess. 1996 DEC; 2(4): 892-919.

131 Jeong J, Mauldin PD. Estimating the weighting components of a health quality index. Biometrical Journal 1996; 38(7): 779-790.

132 Lew CS, Mills WB, Wilkinson KJ, Gherini SA. RIVRISK: A model to assess potential human health and ecological risks from chemical and thermal releases into rivers. Water Air and Soil Pollution 1996 JUL; 90(1-2): 123-132.

133 Lipfert FW, Moskowitz PD, Fthenakis VE, Saroff L. Probabilistic assessment of health risks of methylmercury from burning coal. Neurotoxicology 1996 SPR; 17(1): 197-211.

134 Weinberg J. The Impact of Aging upon the Need for Medical Beds-a Monte-Carlo Simulation. J. Public Health Med. 1995 SEP; 17(3): 290-296.

135 Hattis D, Silver K. Human Interindividual Variability-a Major Source of Uncertainty in Assessing Risks for Noncancer Health-Effects. Risk Analysis 1994 AUG; 14(4): 421-431.

136 Smith RL. Use of a Monte-Carlo Simulation for Human Exposure Assessment at the Superfund Site. Risk Analysis 1994 AUG; 14(4): 433-439.

137 Eltahtawy AA, Jackson AJ, Ludden TM. Comparison of Single and Multiple-Dose Pharmacokinetics using Clinical Bioequivalence Data and Monte-Carlo Simulations. Pharm. Res. 1994 SEP; 11(9): 1330-1336.

138 Javitt JC, Aiello LP, Chiang YP, Ferris FL, Canner JK, Greenfield S. Preventive Eye Care in People with Diabetes is Cost-Saving to the Federal-Government-Implications for Health-Care Reform. Diabetes Care 1994 AUG; 17(8): 909-917.

139 Chrischilles E, Shireman T, Wallace R. Costs and Health-Effects of Osteoporotic Fractures. Bone 1994 JUL-AUG; 15(4): 377-386.

140 Schulman KA, Mcdonald RC, Lynn LA, Frank I, Christakis NA, Schwartz JS. Screening Surgeons for HIVInfection-Assessment of a Potential Public-Health Program. Infection Control and Hospital Epidemiology 1994 MAR; 15(3): $147-155$.

141 Thompson KM, Burmaster DE, Crouch EAC. Monte-Carlo Techniques for Quantitative Uncertainty Analysis in Public-Health Risk Assessments. Risk Analysis 1992 MAR; 12(1): 53-63.

142 Paustenbach DJ, Meyer DM, Sheehan PJ, Lau V. An Assessment and Quantitative Uncertainty Analysis of the Health Risks to Workers Exposed to Chromium Contaminated Soils. Toxicol. Ind. Health 1991 MAY; 7(3): 159-196.

the target attainment rates obtained with these simulations. Studies of these kinds usually derive their data from clinical trials.
Prognostic and transmission models of health interventions MCS is extensively used to measure the number and impact of medical interventions for the prevention of disease 
deterioration or disease transmission. Many intervention procedures with medical treatment show substantial reductions in disease morbidity or mortality. However, their use is expensive and to some extent determined by local practice, with great variation in the rates of these procedures. The optimum level of such procedures may therefore be uncertain, and this uncertainty is a major problem for both clinicians and health service administrators. It is therefore important to have methods that model the requirements for these interventions at the population level by capturing the movement of individuals between different states based on disease and/or procedure history. Such interventions that usually involve patients or disease transmission stages use Markov processes to measure the probabilities of transmission. MCS analysis of the Markov process is the most useful model for this situation, which also allows the enumeration of events as individuals move between states [MC1, 2, 22, 22, 32, 39, 48, 57, 58, 59, 64, 66, 75, 84, 91, 94, 99]. Moreover, there are studies that seek to develop criteria that classify risk factor levels during intervention or treatment outcomes after intervention. In such studies, regression analysis is the most commonly used tool (some others are Bayesian statistics and bootstrapping) that specifies the inclusion criteria or variables. MCS is used in addition to this method to investigate the robustness of these variables or classification criteria [MC49, 74]. Subsequently, in these studies, MCS techniques evaluate the propagation of the variability of input parameters used in regression models by analysing the effects of uncertainty and the intrinsic variability of parameters.

Cost-benefit analysis and policy evaluation of medical treatment and disease management programmes The above research can easily be adapted or expanded to fit economic data, which evaluate the cost-effectiveness of specific interventions, treatments, tests and health programmes. Certain medical conditions have a profound and growing impact on healthcare resource utilisation. In many circumstances the direct expenditures for screening or treatment (with drugs or other therapy) of these conditions have substantially increased due to the overall ageing of the population. Therefore, research in this field tries to assess the economic value of a population-based screen-and-treat strategy for diseases or medical conditions compared to alternative strategies or no intervention [MC6, 7, 9, 12, 16, 23, 25, 35, 37, 38, 39, $40,44,45,46,50,60,63,65,68,70,72,73,82,83,87,89$, 92, 96, 101, 108, 109, 112, 117, 120, 131, 138, 139]. Briefly, a Markov state transition model with different health states is developed to simulate the medical condition fractures or disease states as a function of demographic change and other influences allowing for a wide variety of scenarios regarding planned medication usage, drug efficacy and individual persistence with treatment. The cost-effectiveness of these alternative strategies is evaluated in an MCS-based incremental cost-utility analysis. The main outcome is usually cost per quality-adjusted life year gained. These results provide policymakers with a common metric for comparing diverse technologies and programmes. Model inputs for the simulation models are usually obtained from published literature and surveys, expert interviews and clinical trials and studies.

Miscellaneous There are a number of MCS studies emerging from our search strategy that form smaller categories or do not clearly fall within a distinguished category. These studies are literature review studies and taxonomies of various statistical methods, including Monte Carlo simulation, which can be useful decision tools pertaining to a particular health problem and usually pertinent to risk assessment [MC11, 27, 81]. Other studies focus on the development of new methods, for example, probabilistic public health risk assessment/treatments or improvement of an existing modelling method or comparison between different methods in the form of feasibility studies $[\mathrm{MC} 8,18,30,36,60,69,78,86,105$, $110,115,121,123,129,130,141,142]$ (16 papers). Finally, there are MCS studies about health surveys and service delivery examination, including, for example, the determinants of health and measures of health status, the quality of hospital care and the impact of demographic change on the need for hospital resources [MC23, 104, 107, 134].

Discrete-Event Simulation This is the second most popular category in our study with 40 papers overall after screening (Table 4). It is said that DES can create significantly more insight than MCS in areas such as health economics (Eldabi et al, 2000). Applications of DES in health have been clustered under the following headings: (a) planning of healthcare services described in 13 papers in our search; (b) health economic models that are presented in 10 papers; (c) seven review and six methodology papers; and (d) contagious disease interventions presented in four papers.

An extensive taxonomy of DES studies in healthcare over the past 20 years is presented in Jun et al (1999) and Fone et al (2003). The study conducted by Fone et al (2003) is a systematic review from 1980 to 1999 . Our DES categories bring some similarities to those identified by Fone et al (costs of illness and economic evaluation, hospital scheduling and organisation, infection and communicable disease, screening and miscellaneous). The work carried out by Jun et al (1999) is a survey, specifically, on the applications of DES to healthcare clinics over the 1980s up to 1997. The categories identified by Jun et al (patient scheduling and admissions, patient flow schemes, and staff scheduling on patient flow and work flow, allocation of resources when sizing and planning beds, rooms, and staff personnel) also bear resemblance to our sub-categories in 'Planning healthcare services', as the latter study is focused on a specific area of DES and is more analytic. We now discuss each of our DES categories according to the number of publications identified in each cluster in a descending order. 
Table 4 DES papers included in the present study

S No. DES paper

1 Scherrer CR, Griffin PM, Swann JL. Public health sealant delivery programs: Optimal delivery and the cost of practice acts. Medical Decision Making 2007 NOV-DEC; 27(6): 762-771.

2 Duguay C, Chetouane F. Modelling and improving emergency department systems using discrete event simulation. Simulation-Transactions of the Society for Modelling and Simulation International 2007 APR; 83(4): 311-320.

3 Ward A, Bozkaya D, Fleischmann J, Dubois D, Sabatowski R, Caro JJ. Modelling the economic and health consequences of managing chronic osteoarthritis pain with opioids in Germany: comparison of extended-release oxycodone and OROS hydromorphone. Curr. Med. Res. Opin. 2007 OCT; 23(10): 2333-2345.

4 Hollingworth W, Spackman DE. Emerging methods in economic Modelling of imaging costs and outcomes: A short report on discrete event simulation. Acad. Radiol. 2007 APR; 14(4): 406-410.

5 Cooper K, Brailsford SC, Davies R. Choice of modelling technique for evaluating health care interventions. J. Oper. Res. Soc. 2007 FEB; 58(2): 168-176.

6 Vasilakis C, Sobolev BG, Kuramoto L, Levy AR. A simulation study of scheduling clinic appointments in surgical care: individual surgeon versus pooled lists. J. Oper. Res. Soc. 2007 FEB; 58(2): 202-211.

$7 \quad$ Katsaliaki K, Brailsford SC. Using simulation to improve the blood supply chain. J. Oper. Res. Soc. 2007 FEB; 58(2): $219-227$.

8 Ceglowski R, Churilov L, Wasserthiel J. Combining Data Mining and Discrete Event Simulation for a value-added view of a hospital emergency department. J. Oper. Res. Soc. 2007 FEB; 58(2): 246-254.

9 Eldabi T, Paul RJ, Young T. Simulation modelling in healthcare: reviewing legacies and investigating futures. J. Oper. Res. Soc. 2007 FEB; 58(2): 262-270.

10 Brennan A, Chick SE, Davies R. A taxonomy of model structures for economic evaluation of health technologies. Health Econ. 2006 DEC; 15(12): 1295-1310.

11 Aaby K, Herrmann JW, Jordan CS, Treadwell M, Wood K. Montgomery Countys Public Health Service uses operations research to plan emergency mass dispensing and vaccination clinics. Interfaces 2006 NOV-DEC; 36(6): 569-579. Hollocks BW. Forty years of discrete-event simulation-a personal reflection. J. Oper. Res. Soc. 2006 DEC; 57(12): 1383-1399. Caro JJ, Guo S, Ward A, Chalil S, Malik F, Leyva F. Modelling the economic and health consequences of cardiac resynchronization therapy in the UK. Curr. Med. Res. Opin. 2006 JUN; 22(6): 1171-1179.

14 Caro J, Ward A, Moller J. Modelling the health benefits and economic implications of implanting dual-chamber vs. singlechamber ventricular pacemakers in the UK. Europace 2006 JUN; 8(6): 449-455.

15 Heeg BMS, Buskens E, Knapp M, van Aalst G, Dries PJT, de Haan L, et al. Modelling the treated course of schizophrenia: Development of a discrete event simulation model. Pharmacoeconomics 2005; 23: 17-33.

16 Willis BH, Barton P, Pearmain P, Bryan S, Hyde C. Cervical screening programmes: canautomation help? Evidence from systematic reviews, an economic analysis and a simulation modelling exercise applied to the UK. Health Technol.Assess. 2005 MAR; 9(13): 1-207, iii.

17 Shechter SM, Bryce CL, Alagoz O, Kreke JE, Stahl JE, Schaefer AJ, et al. A clinically based discrete-event simulation of end-stage liver disease and the organ allocation process. Medical Decision Making 2005 MAR-APR; 25(2): 199-209. Harper PR, Shahani AK, Gallagher JE, Bowie C. Planning health services with explicit geographical considerations: a stochastic location-allocation approach. Omega-International Journal of Management Science 2005 APR; 33(2): 141-152.

Rauner MS, Brailsford SC, Flessa S. Use of discrete-event simulation to evaluate strategies for the prevention of mother-to-child transmission of HIV in developing countries. J. Oper. Res. Soc. 2005 FEB; 56(2): 222-233.

20 Connelly LG, Bair AE. Discrete event simulation of emergency department activity: A platform for system-level operations research. Acad. Emerg. Med. 2004 NOV; 11(11): 1177-1185.

21 Stahl JE, Rattner D, Wiklund R, Lester J, Beinfeld M, Gazelle GS. Reorganizing the system of care surrounding laparoscopic surgery: A cost-effectiveness analysis using discrete-event simulation. Medical Decision Making 2004 SEP-OCT; 24(5): 461-471. Karnon J. Alternative decision modelling techniques for the evaluation of health care technologies: Markov processes versus discrete event simulation. Health Econ. 2003 OCT; 12(10): 837-848.

Vieira IT, Harper PR, Shahani AK, de Senna V. Mother-to-child transmission of HIV: a simulation-based approach for the evaluation of intervention strategies. J. Oper. Res. Soc. 2003 JUL; 54(7): 713-722. Ingolfsson A, Erkut E, Budge S. Simulation of single start station for Edmonton EMS. J. Oper. Res. Soc. 2003 JUL; 54(7): 736-746.

25 Brailsford S, Schmidt B. Towards incorporating human behaviour in models of health care systems: An approach using discrete event simulation. Eur. J. Oper. Res. 2003 OCT 1; 150(1): 19-31.

26 Hupert N, Mushlin AL, Callahan MA. Modelling the public health response to bioterrorism: Using discrete event simulation to design antibiotic distribution centers. Medical Decision Making 2002 SEP-OCT; 22(5): S17-S25. Davies R, Roderick P, Canning C, Brailsford S. The evaluation of screening policies for diabetic retinopathy using simulation. Diabetic Med. 2002 SEP; 19(9): 762-770. Swisher JR, Jacobson SH, Jun JB, Balci O. Modelling and analyzing a physician clinic environment using discrete-event simulation. Comput. Oper. Res. 2001 FEB; 28(2): 105-125.

29 Moreno L, Aguilar RM, Martin CA, Pineiro JD, Estevez JI, Sigut JF, et al. Patient-centered simulation to aid decision-making in hospital management. Simulation 2000 MAY; 74(5): 290-304.

30 Groothuis S, van Merode GG. Discrete event simulation in the health policy and management program. Methods Inf. Med. 2000 DEC; 39(4-5): 339-342.

31 Eldabi T, Paul RJ, Taylor SJE. Simulating economic factors in adjuvant breast cancer treatment. J. Oper. Res. Soc. 2000 APR; 51(4): 465-475. 
Table 4 (Continued)

\begin{tabular}{ll}
\hline S No. & DES paper \\
\hline 32 & Jun JB, Jacobson SH, Swisher JR. Application of discrete-event simulation in health care clinics: A survey. J. Oper. Res. Soc. \\
33 & 1999 FEB; 50(2): 109-123. \\
Davies R, Roderick P. Planning resources for renal services throughout UK using simulation. Eur. J. Oper.Res. 1998 MAR 1; \\
105(2): 285-295. \\
Hart WM, Espinosa C, Rovira J. A simulation model of the cost of the incidence of IDDM in Spain. Diabetologia 1997 MAR; \\
40(3): 311-318. \\
Dittus RS, Klein RW, DeBrota DJ, Dame MA, Fitzgerald JF. Medical resident work schedules: Design and evaluation by \\
simulation Modelling. Management Science 1996 JUN; 42(6): 891-906. \\
Davies R, Canning C. Discrete event simulation to evaluate screening for diabetic eye disease. Simulation 1996 APR; 66(4): \\
209-216. \\
$\begin{array}{l}\text { Steward D, Standridge CR. A veterinary practice simulator based on the integration of expert system and process Modelling. } \\
\text { Simulation 1996 MAR; 66(3): 143-159. }\end{array}$ \\
$\begin{array}{l}\text { Davies HTO, Davies R. Simulating Health Systems-Modelling Problems and Software Solutions. Eur. J. Oper. Res. 1995 } \\
\text { NOV 16; 87(1): 35-44. }\end{array}$ \\
$\begin{array}{l}\text { Davies R, Davies HTO. Modelling Patient Flows and Resource Provision in Health Systems. Omega-International Journal of } \\
\text { Management Science 1994 MAR; 22(2): 123-131. }\end{array}$ \\
Irvine SR, Levary RR. A Discrete-Event Simulation of the Mcdonnell Douglas Health Information-Systems Online Executive. \\
Comput. Oper. Res. 1988; 15(6): 535-549.
\end{tabular}

Planning of healthcare services and health interventions DES allows decision makers to effectively assess the efficiency of existing healthcare delivery systems such as hospitals [DES29], to improve system performance or design and to plan new ones in a risk-free and costless environment by investigating the complex relationships among the different model variables (ie rate of arrivals, time spent in the system, etc) and overcoming bottlenecks. The scope of evaluation can be micro in scale, for example by examining resource needs in terms of scheduling staff and measuring bed and equipment capacity at individual clinics, or macro in proportion (healthcare policy for the entire population). DES allows the decision makers to gather insights and obtain approximate results of the differing but competing policies that may be implemented in the future. Moreover, since DES allows the creation of dynamic population-based models, wherein each entity in the simulation represents an individual, the results could indicate the number of people who may be affected by the adoption of a particular strategy.

Some of the applications of DES therefore relate to managing patient admissions and staff scheduling, for example DES studies that compared the 'individual surgeons' strategy with the 'pooled lists' strategy for scheduling outpatient clinical appointments in surgical care [DES6]; designed a new house staff work schedule [DES35] and ambulance schedules [DES24]. They also relate to identifying areas of improvement of service through possible reorganisation of existing resources, for example; reorganisation of surgical and anaesthesia care surrounding laparoscopic surgery [DES21]; experimenting with real-time health information system to reduce response time [DES40]; evaluating operating policies in clinical environments [DES28] and allocation policies for liver transplantation [DES17]; forecasting the impact of changing demand for treatment of irreversible renal failure [DES33] and planning for the geographical locations of new healthcare services taking into account the demographics of the population and the location of the patients who need the services [DES18]. Furthermore, DES is well-suited to tackle problems in A\&E departments, where resources are scarce and patients arrive at irregular times [DES2], and effectively combine Total Quality Management strategies [DES24] and data mining [DES8] for better results. Moreover, DES applications relate to estimating performance measures impacting facilities design and planning of veterinary practice [DES37]. As large majorities of the population depend on edible products or by-products from livestock, the health of livestock has a significant effect on public health.

Health economic models Health economic models evaluate the health implications and the economic costs of providing healthcare to the population at large. They usually do so by comparing alternative healthcare interventions aiming to maximise welfare through optimal utilisation of the allocated public health funds. With respect to health economic models, the use of DES has been reported for evaluating, among others, the cost of providing dental care to children [DES1]; for comparing methods of managing chronic osteoarthritis pain [DES3]; for modelling the treated course of schizophrenia so as to estimate the long-term costs and effects of new interventions [DES15]; for evaluating the cost effectiveness of screening strategies for diabetic retinopathy by varying the screening method and interval [DES27, 36] and of introducing a range of automated image analysis systems for cervical screening programmes [DES16]; and for estimating the cost-effectiveness and the direct healthcare costs pertaining to insulin-dependent diabetes mellitus [DES34]. The use of DES health economic models have also been reported for the economic evaluation of pacemakers. For example, DES was used for modelling the health benefits and economic implications of implanting dual-chamber versus 
single-chamber ventricular pacemakers in the UK [DES14] and of implanting a Cardiac Resynchronization device of Therapy for reducing heart failure as opposed to Optimum Pharmacologic Therapy that does not require a pacemaker [DES13]. DES was also used to improve the National Blood Service supply chain by investigating different blood ordering and distribution policies [DES7].

Review and methodology papers Our research methodology identified a number of review papers in the healthcare literature. Some of these papers compared modelling techniques used in healthcare, such as DES, Markov and semi-Markov chain models, queuing models and deterministic models (in the context of patient flow models [DES39] and economic evaluations of healthcare technologies [DES22]) and presented taxonomies of modelling structures [DES5, $10,32]$. Other papers present a personal reflection of DES [DES12] and outline a vision of the future use of simulation in healthcare [DES9]. They all found DES to be particularly suitable for estimating cost and health benefits of dynamic population-based models with individual attributes and patient care systems with scarce resources.

In our search, five methodology papers were identified. They deal with various issues such as the use of patientchart-driven computer simulation to advance A\&E system [DES20]; the use of DES as one emerging modelling technique for supporting decision making in randomized clinical trials of breast cancer [DES31], for modelling patient behaviour when screening for diabetic retinopathy [DES25] and for evaluating imaging technologies [DES4]. Moreover, DES has been acknowledged as a well-suited methodology for modelling health systems [DES38] and a valuable training tool for students who learnt to analyse and design efficiently work-flow processes in healthcare [DES30].

Contagious disease interventions DES applications in this category usually relate to proposing ways to suppress the spread of HIV in developing countries [DES19, 23], and to the public response to control the outbreak of contagious diseases that may be caused by natural occurrence [DES11] or an act of terrorism [DES26]. These DES models are developed to plan emergency clinics and distribution centres for massdispensing and vaccination.

System Dynamics SD can assist the design of healthcare policies by examining how the fundamental structure might influence the progressive behaviour of a system. It takes into consideration factors such as the time variation of both the tangible elements, such as waiting times and healthcare costs, as well as intangible elements, such as patient anxiety and the effects of various pressures on purchasing decisions (Taylor and Lane, 1998).

Seventeen studies are counted under this technique. The papers pertaining to SD have been categorised under the following headings: (a) public health policy evaluation and economic models, represented in nine papers in our search; (b) modelling healthcare systems and infrastructure disruption (four papers); (c) use of SD as a training tool (three papers); and (d) one review paper of SD for modelling public health matters of disease epidemiology and healthcare capacity [SD6]. The first three categories are described below in the same order as above. The papers are listed in Table 5.

Public health policy evaluation and economic models SD has been applied for the evaluation of several public health policies. With regard to communicable diseases, SD models were developed to estimate the effect of harm reduction policies for HIV/AIDS and tuberculosis (such as 'needle-sharing and injection-frequency among drug users and multi-drug resistant tuberculosis control [SD2]) and to assess economic consequences of testing and treating pregnant women for HIV virus with different regimens to avoid prenatal transmission [SD16]. Moreover, SD was used in several studies to evaluate the long-term health impact of smoking by comparing policies such as increasing cigarette excise taxes, raising the legal smoking age to 21 [SD4] and introducing tobacco harm reduction policies [SD8, 9, 11]. They suggested that a large tax increase would have the largest and most immediate effect on smoking prevalence. Control over the cigarette content would bring a net gain in population health, although 'healthier' cigarettes make smoking more attractive and increase tobacco consumption. SD has also been used by health planners to gain a better understanding of diabetes population dynamics [SD7]; to model the feedback effects of reconfiguring health services [SD10] by shifting towards the primary level and bringing services 'closer to home'; to investigate the impact of privacy legislation in the individual health insurance market and the social costs that are borne when applicants do not divulge private information about their medical conditions [SD14].

Modelling healthcare systems and infrastructure disruptions A healthcare system consists of many individual sub-parts that interact with each other, for example the national health system (NHS) consists of vast numbers of GP clinics, walkin centres, hospitals, tertiary care centres, A\&E, IT infrastructure, NHS supply chains, etc. SD allows modelling of several sub-parts of these complex healthcare systems, such as a city's delivery of emergency and on-demand, unscheduled care [SD12], an A\&E dynamics of demand pattern, resource deployment and parallel hospital processes [SD15]. In this regard, SD also has the potential to simulate multiple, independent key elements of an infrastructure. Innovative modelling and analysis framework based on SD could study the entire system of physical and economic infrastructures, and specifically of healthcare facilities, and propose public responses to infrastructure disruptions [SD5] and disasters [SD1], as well as to reduce the devastating health effects of such phenomena by modelling into a unified whole the relief 
Table 5 SD papers included in the present study

S No. SD paper

1 Arboleda CA, Abraham DM, Lubitz R. Simulation as a tool to assess the vulnerability of the operation of a health care facility. J. Perform. Constr. Facil. 2007 JUL-AUG; 21(4): 302-312.

2 Atun RA, Lebcir RM, Mckee M, Habicht J, Coker RJ. Impact of joined-up HIV harm reduction and multidrug resistant tuberculosis control programmes in Estonia: System dynamics simulation model. Health Policy 2007 MAY; 81(2-3): 207-217.

3 Hsieh JL, Sun CT, Kao GYM, Huang CY. Teaching through simulation: Epidemic dynamics and public health policies. Simulation-Transactions of the Society for Modelling and Simulation International 2006 NOV; 82(11): 731-759.

4 Ahmad S, Billimek J. Limiting youth access to tobacco: Comparing the long-term health impacts of increasing cigarette excise taxes and raising the legal smoking age to 21 in the United States. Health Policy 2007 MAR; 80(3): 378-391.

5 Min HSJ, Beyeler W, Brown T, Son YJ, Jones AT. Toward Modelling and simulation of critical national infrastructure interdependencies. IIE Transactions 2007 JAN; 39(1): 57-71.

6 Homer JB, Hirsch GB. System dynamics Modelling for public health: Background and opportunities. Am. J. Public Health 2006 MAR; 96(3): 452-458.

7 Jones AP, Homer JB, Murphy DL, Essien JDK, Milstein B, Seville DA. Understanding diabetes population dynamics through simulation Modelling and experimentation. Am. J. Public Health 2006 MAR; 96(3): 488-494.

8 Ahmad S. Closing the youth access gap: The projected health benefits and cost savings of a national policy to raise the legal smoking age to 21 in the United States. Health Policy 2005 DEC; 75(1): 74-84.

9 Ahmad S, Billimek J. Estimating the health impacts of tobacco harm reduction policies: A simulation Modelling approach. Risk Analysis 2005 AUG; 25(4): 801-812.

10 Taylor K, Dangerfield B. Modelling the feedback effects of reconfiguring health services. J. Oper. Res. Soc. 2005 JUN; 56(6): 659-675.

11 Tengs TO, Ahmad S, Moore R, Gage E. Federal policy mandating safer cigarettes: A hypothetical simulation of the anticipated population health gains or losses. Journal of Policy Analysis and Management 2004 FAL; 23(4): 857-872.

12 Brailsford SC, Lattimer VA, Tarnaras P, Turnbull JC. Emergency and on-demand health care: modelling a large complex system. J. Oper. Res. Soc. 2004 JAN; 55(1): 34-42.

13 Charles BG, Duffull SB. Pharmacokinetic software for the health sciences-Choosing the right package for teaching purposes. Clin. Pharmacokinet. 2001; 40(6): 395-403.

14 Thatcher ME, Clemons EK. Managing the costs of informational privacy: Pure bundling as a strategy on the individual health insurance market. J. Manage. Inf. Syst. 2000 FAL; 17(2): 29-57.

15 Lane DC, Monefeldt C, Rosenhead JV. Looking in the wrong place for healthcare improvements: A system dynamics study of an accident and emergency department. J. Oper. Res. Soc. 2000 MAY; 51(5): 518-531.

16 Anderson JG, Anderson MM. HIV screening and treatment of pregnant women and their newborns: Asimulation-based analysis. Simulation 1998 OCT; 71(4): 276-284.

17 Navarro JDS, Alvarez JAT, Ortega FP, Casado MPS, Polo MP. A Dynamo Application of Microcomputer-Based Simulation in Health-Sciences Teaching. 1993: 30(5): 425-436

Table 6 ABS papers included in the present study

\section{S No. ABS paper}

1 Abbott RG, Forrest S, Pienta KJ. Simulating the hallmarks of Cancer. Artif. Life 2006 FAL; 12(4): 617-634.

2 Boulos MNK, Cai Q, Padget JA, Rushton G. Using software agents to preserve individual health data confidentiality in microscale geographical analyses. J. Biomed. Inform. 2006 APR; 39(2): 160-170.

effort of evacuations, provision of temporary shelters, restoration of electricity and communication lines, etc.

Training SD has also been used as a tool for training health policymakers. It can facilitate the understanding of the dynamics of an epidemic such as SARS [SD3] and explore the applicable combinations of prevention or suppression strategies. Moreover, SD provides an opportunity in some educational environments such as in health sciences by allowing students to experiment in the classroom with the use of professional tools. SD software together with calculator-simulators has been used for teaching pharmacokinetics [SD13], and pharmacological system dynamics models have also been developed for the same purpose [SD17].

Agent-Based Simulation Applications of ABS in the healthcare sector are not yet widespread but it has been used to study problems such as the spread of epidemics (Bagni et al, 2002). The research methodology that we have followed in our review has identified only two papers that have used ABS. The papers are listed in Table 6.

One study reported an ABS model called CancerSIM, which allows researchers to study the dynamics and interactions of cancer hallmarks and possible therapies [ABS1]. The other study [ABS2] used software agents to 
preserve individual health data confidentiality in micro-scale geographical analyses and showed that by limiting the accuracy of geocodes for the purposes of privacy protection, the ability to identify areas of high disease risk is degraded.

The five papers that report on several simulation techniques (refer to Table 1) have been included in the MCS and the DES category for the sake of simplicity. Three papers report both on MCS and DES and were described under the 'Prognostic and transmission models of health interventions' [MC48, 58] and the 'Cost-benefit analysis and policy evaluation of medical treatment and disease management programs' [MC65] headings of MCS. Moreover, there are two papers that were described under the 'Review papers' heading of DES. A review paper [DES9] that refers simultaneously to DES, SD and MCS and a taxonomy paper [DES10] that refers to DES and SD among other operational research techniques.

\section{Research impact}

In this section, we present the citation statistics of a few highly cited papers in the field of healthcare simulation (objective 3) (Table 7). The table shows the total citations and the average article citations as a means of identifying the impact of these publications. The list is sorted (and therefore publications for inclusion in Table 7 are selected) based on the total citation count. However, the authors recognise that the average citation is also a very useful measure as it eliminates the discrepancies caused by the number of years passed since publication. It is generally expected that review papers have more citations than research papers. It is therefore surprising that none of the papers included in the list are review papers. Even more surprising is the fact that all papers use the MCS technique as their main method of analysis. Many of the papers in Table 7 present costeffectiveness analyses of specific healthcare applications or disease prevention methods, including the first paper that was published in the journal Bone in 1994.

It should be noted here that a good number of journals in Table 7 are either medical or health-related journals. It is widely accepted that medical journals generally have citations that are much higher compared to the OR journals, from which it might be concluded that impact is not incomparable between them. A more stratified representation would shed more light. However, this was out of the main scope of this study.

\section{Results implementation, funding sources and analysis of simulation software}

In this section, we examine the evidence of results presentation, implementation (objective 4), funding (objective 5) and software usage (objective 6) from among those papers that were selected for inclusion in this study after screening.

Of the 201 papers, $184(91 \%)$ present results and have a separate, typically large section supported with tables and graphs to give a full analysis and explanation to the readers. There are seven MCS papers, eight DES, three SDS and one ABS paper, which do not present results. Of these, the majority are review and methodology papers. There are only five papers that fall in other categories (health risk assessment; health economic model; planning of healthcare services) and do not demonstrate results in a numerical format in the way described above. Yet, implementation of research results is hardly mentioned in these publications, with only a few papers (11 out of $201,5.4 \%$ ) reporting on the implementation of results to the stakeholder organisations, in which the case studies were based. Six are reported in the MCS category,

Table 7 Publications with high number of citations

\begin{tabular}{|c|c|c|}
\hline Total citations & Average citations & Publication \\
\hline 166 & 11.07 & $\begin{array}{l}\text { 1. Chrischilles E, Shireman T, Wallace R. Costs and Health-Effects of Osteoporotic Fractures. } \\
\text { Bone } 1994 \text { JUL-AUG; 15(4): 377-386. }\end{array}$ \\
\hline 134 & 8.93 & $\begin{array}{l}\text { 2. Javitt JC, Aiello LP, Chiang YP, Ferris FL, Canner JK, Greenfield S. Preventive Eye Care } \\
\text { in People with Diabetes is Cost-Saving to the Federal-Government-Implications for } \\
\text { Health-Care Reform. Diabetes Care } 1994 \text { AUG; 17(8): 909-917. }\end{array}$ \\
\hline 102 & 6 & $\begin{array}{l}\text { 3. Thompson KM, Burmaster DE, Crouch EAC. Monte-Carlo Techniques for Quantitative } \\
\text { Uncertainty Analysis in Public-Health Risk Assessments. Risk Analysis } 1992 \text { MAR; 12(1): } \\
\text { 53-63. }\end{array}$ \\
\hline 76 & 9.5 & $\begin{array}{l}\text { 4. Nichol KL. Cost-benefit analysis of a strategy to vaccinate healthy working adults against } \\
\text { influenza. Arch. Intern. Med. } 2001 \text { MAR 12;161(5): 749-759. }\end{array}$ \\
\hline 67 & 8.38 & $\begin{array}{l}\text { 5. Ambrose PG, Grasela DM. The use of Monte Carlo simulation to examine } \\
\text { pharmacodynamic variance of drugs: fluoroquinolone pharmacodynamics against } \\
\text { Streptococcus pneumoniae. Diagn. Microbiol. Infect. Dis. } 2000 \mathrm{NOV} \text {; 38(3): 151-157. }\end{array}$ \\
\hline 46 & 2.56 & $\begin{array}{l}\text { 6. Nieuwenhuijsen M, Paustenbach D, Duarte-Davidson R. New developments in exposure } \\
\text { assessment: The impact on the practice of health risk assessment and epidemiological } \\
\text { studies. Environ. Int. } 2006 \text { DEC; 32(8): 996-1009. }\end{array}$ \\
\hline 42 & 2.8 & $\begin{array}{l}\text { 7. Hattis D, Silver K. Human Interindividual Variability-a Major Source of Uncertainty in } \\
\text { Assessing Risks for Noncancer Health-Effects. Risk Analysis } 1994 \text { AUG; 14(4): 421-431. }\end{array}$ \\
\hline 35 & 3.5 & $\begin{array}{l}\text { 8. Briggs AH, Mooney CZ, Wonderling DE. Constructing confidence intervals for } \\
\text { cost-effectiveness ratios: An evaluation of parametric and non-parametric techniques using } \\
\text { Monte Carlo simulation. Stat. Med. } 1999 \text { DEC 15;18(23): 3245-3262. }\end{array}$ \\
\hline
\end{tabular}


Table 8 Research funding sources

\begin{tabular}{lcc}
\hline Funding source & No. of papers & Percentage \\
\hline Department of Health & 13 & 12.7 \\
National Foundations/Centres & 13 & 12.7 \\
Pharmaceutical Companies & 12 & 11.8 \\
Other Governmental Departments & 11 & 10.8 \\
National Institutes for Health-related Research & 11 & 10.8 \\
Universities/Colleges & 9 & 8.8 \\
National Research Council & 9 & 8.8 \\
Health/environment Research Agencies & 6 & 5.9 \\
European Research Programs & 4 & 3.9 \\
Non-Pharmaceutical Companies & 3 & 2.9 \\
Private Foundations & 3 & 2.9 \\
Funding Organisations for Academic Research & 3 & 2.9 \\
National Health Services & 3 & 2.9 \\
Health Authorities & 2 & 100.0 \\
Sum & $\mathbf{1 0 2}$ \\
\hline
\end{tabular}

Table 9 Monte Carlo Simulation software

\begin{tabular}{lrr}
\hline MCS software & No. of papers & Percentage \\
\hline @Risk & 10 & 23.3 \\
Crystal Ball & 10 & 23.3 \\
Excel & 3 & 7.0 \\
SimHerd & 2 & 4.7 \\
NONMEM & 2 & 4.7 \\
Matlab & 2.7 \\
WinBUGS & 2 \\
RIVRISK, SimTools, Mathematica ${ }^{\circledR}$, GENMM.exe, ITOUGH, & 4.7 \\
DATA 3.5 for Healthcare, BASIC, Stata, Hexalog, Java, C11, SAS & 1 \\
Sum & 2.3 \\
\hline
\end{tabular}

four in DES and one in SD. However, this is not to say that the case-oriented simulation studies that have not implemented their results have gone astray. Neither should it be implied that their impact is only academic and does not reflect the real world. Looking further at the issue, one may realise that healthcare simulation studies generally have a long gestation period before they reach the ultimate decision makers in a comprehensive format. These decision makers need to decide among a plethora of similar studies, taking into consideration various other factors, and come to a conclusion of turning a specific recommendation from a study into a policy applicable in health organisations and settings. Subsequently, it is unlikely that implementation will be part of the paper. Moreover, researchers are eager to publish once they have the first results in hand and only very occasionally will they wait until the impact of their method is shown in the real world in order to incorporate it into their paper.

Perhaps a better measure of the interest in the research being conducted in the healthcare simulation studies is the funding process. Of the 201 studies, 87 (43\%) have received full or partial funding. Of the 163 identified MCS studies, around 39\% mention their project's funding source, $48 \%$ of the DES papers, $65 \%$ of the SD papers and $100 \%$ of the ABS papers (two papers) report a funding source. Many of these papers refer to various sources of funding. Table 8 illustrates some of these sources. As can be seen from the table, health departments and national foundations are the major sources of funding, closely followed by pharmaceutical companies. Other governmental departments and national institutions also fund healthcare studies. Funds for research are also derived from internal University funding and research council grants.

From our sampled list of papers, we find that funding seems to be consistent throughout the years. This suggests that there is no identified trend that more funding is provided for healthcare research over the last years or vice versa.

Finally, we conclude by presenting some statistics on simulation software/programming languages that were used to support model development in the selected studies. It is important to mention that, from our sample of 201 selected papers, only 83 papers acknowledge the software or programming language that was used to develop the model. This data is presented in Table 9 (MCS software), Table 10 (DES software) and Table 11 (SD software), respectively. With regard to MCS (Table 9), @Risk and Crystal Ball were among the most popular software, followed by Excel. Numerous other 
Table 10 Discrete Event Simulation software

\begin{tabular}{|c|c|c|}
\hline DES Software & No. of papers & Percentage \\
\hline Arena & 6 & 20.7 \\
\hline Borland Delphi (Programming Language) & 5 & 17.2 \\
\hline Simul8 & 3 & 10.3 \\
\hline PASCAL (Programming Language) & 2 & 6.9 \\
\hline AutoMod & 2 & 6.9 \\
\hline SIGMA & 2 & 6.9 \\
\hline $\begin{array}{l}\text { Extend, SIMAN, ServiceModel (Promodel), @ Risk and Excel, SLAMSYSTEM software, } \\
\text { C Program, Visual Basic (Programming Languages), MODSIM, INSIGHT, Visual Simulation } \\
\text { Environment (Orca Computer) simulation language, Statecharts }\end{array}$ & 1 & 3.4 \\
\hline Sum & 29 & 100.0 \\
\hline
\end{tabular}

Table 11 System Dynamics Simulation software

\begin{tabular}{lcc}
\hline SD Simulation software & No. of papers & Percentage \\
\hline Vensim & 5 & 50.0 \\
STELLA & 4 & 40.0 \\
DYNAMO & 1 & 10.0 \\
Sum & $\mathbf{1 0}$ & 100.0 \\
\hline
\end{tabular}

software and programs have also been used, some of them specific to health or other applications.

The process of building DES models involves some form of software. The software can either be a high-level programming language or a Commercial, Off-The-Shelf (COTS) simulation package. DES software Arena is the most popular in this sample review, followed by the programming language Borland Delphi and COTS package Simul8 (Table 10).

As for SD, the use of only few types of software is reported. Vensim is first in the list, closely followed by STELLA. DYNAMO comes last (Table 11).

Finally, one of the two ABS papers reported the use of the programming language $\mathrm{C}++$ to create CancerSIM.

In general, the rapid growth in simulation software technology has created numerous new application opportunities, including more sophisticated implementations, as well as combining simulation and other methods for complex models and processes. Trends from our data analysis suggest that, in the most recent years, COTS packages have taken the lead over one-off models that are coded using programming languages. This is explained by the fact that COTS simulation packages are rapidly evolving through inclusion of more advanced features (eg 3-D graphics, parallel processor support, etc).

\section{Discussion}

The field of healthcare simulation has evolved significantly over the past 30 years. A great number of health problems have been approached with simulation techniques, which have offered greater precision with regard to resource allocations, evaluations between health strategies and risk assessments. In this review paper reflecting on 37 years of healthcare

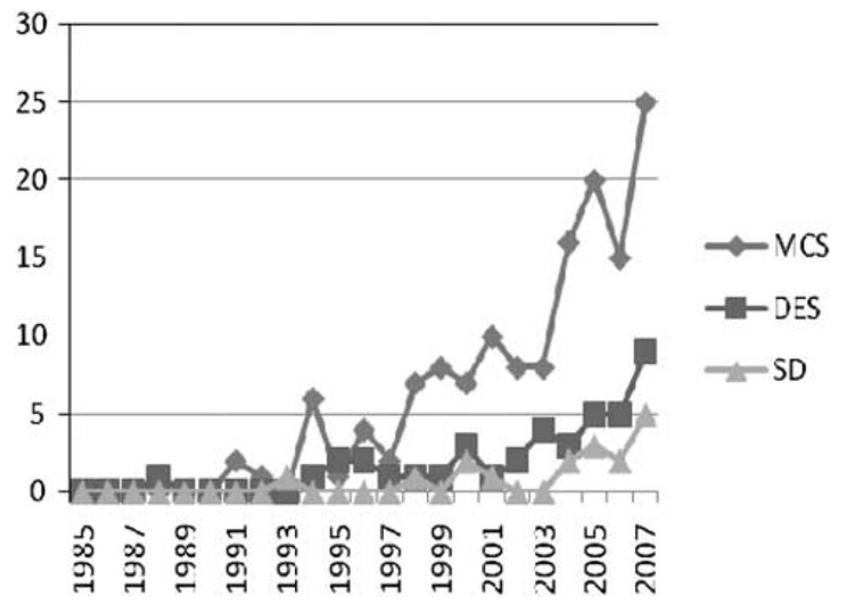

Figure 2 Number of papers per simulation techniques over the years.

simulation, we see some trends that apply to the discipline as a whole.

Looking first at the statistics of our sampled papers, we could derive the conclusion that the proportion of papers published in the field has drastically increased, with more than three-quarters published after 2000. Annual paper contributions amounted from one paper in 1988 to 36 in 2007. It is, however, surprising that the oldest paper in our data set is from 1988 as our search strategy concentrated on identifying healthcare simulation papers published from 1970 onwards. One reason for this is possibly that the number of journals indexed by ISI WoS has swelled with the rising popularity of the Internet and the availability of electronic bibliographical information (this may not have been the case during 1970s-1980s). Furthermore, it is arguable that although simulation has been applied to manufacturing, defence, supply chains etc., for a long time, its application in the healthcare context is comparatively new. Figure 2 illustrates the historical trends of the healthcare modelling papers for each simulation technique (the only exception is ABS which has only two papers). The ascending lines show the increasing number of published papers in the field especially after the 
mid-1990s for all three simulation methods. This is in line with the clear increase in simulation usage in the general service sector from the 1990s onwards (Robinson, 2005). Year-to-date figures suggest that this gradual upward trend will continue. It is apparent that during the last 4 years the published papers in this field have drastically increased. A reason might be the possible increase of funding in recent years (Murphy and Topel, 2003).

Simulation as a technique in health problems is used both as the main methodology of the research and as a supportive method to evaluate the robustness of other methods in different papers. MCS seems to be the most popular simulation technique in health studies, and the majority of papers fall within the health risk assessment category. In this category studies pertaining to air and water pollution, food poisoning and soil contamination are leading in terms of published papers, and drug development and dose-response portion studies follow. Cost-benefit analyses health studies with the use of MCS are also popular. They assess the economic value of population-based screen-and-treat alternative strategies for diseases and medical conditions. Some of these studies hold the first positions in terms of research impact and are found to have the maximum average number of citations in our dataset. Moreover, it is particularly noticeable that of the 142 MCS papers, none were published in an OR journal (as defined by the Association of Business School-ABS list). One reason for this may be that MCS is extensively used by health professionals/academics who wish to publish in health-related outlets, or that OR academics have lost interest in the use of MCS and have focused in the use of other simulation techniques to tackle health problems. Nevertheless, several of the MCS papers identified in our study would fit the aim and scope of OR journals. For example MC7, 8, 9, $23,25,26,2,30,32,38$ and many more.

In the analysis of the research paradigms categories, it is obvious that some overlap exists among the health applications examined by simulation technique. A very apparent example is that all simulation techniques deal with screening strategies and cost-benefit analysis of medical interventions. Assuming that the categorisation of papers was made according to the health problem tackled and regardless of the simulation technique employed, the papers of cost-benefit analysis would be at about the same level of the health risk assessment category. However, many researchers will agree that, although the application area is the same, the extent, the level and the detail at which this is examined differs according to the technique employed. SD takes a holistic approach and thus the health problem or situation is looked at from a more global level to a greater extent. Consequently, this technique is appropriate for facilitating health policy making at the macro-level. DES and ABS examine the health problems in more detail (micro-level), taking into account the properties of individual entities, yet this restricts the extent of the system that can be modelled. Therefore, decisions can usually be reached with the use of DES and
ABS only at the operational level. Monte Carlo simulation incorporates the random sampling element at aggregated level, which makes modelling of population-based diseases easy to handle. When the individual aspect is important then DES is more appropriate. Moreover, DES and SD are more suitable for modelling problems in which the time element plays a significant role, such as utilisation of health services' resources and bed/equipment capacity management. Nonetheless, looking at the categories presented in this study, one can see that health risk assessment is pertinent to MCS modelling; planning of health services is most of the times handled with the DES models (and less with SD); and training of health students and managers is prevalent in the SD approach. Unfortunately, we could not make a distinct category for ABS since the sample was so small. Moreover, a year-by-year analysis of the number of papers in each research paradigm showed that there are no chroni gaps in the identified categories, and for that reason published research in these general fields are continuous.

Relatively few of the published healthcare simulation articles reported significant effects that simulation had on the healthcare system being studied. This may imply that, although authors document the model, the issues they model and the model results, there are few real implementation results to report. England and Roberts (1978) implied that the reasons behind this are either inadequate models that cannot quantify the impact of the human factor, or the diversity of authority in healthcare facilities, which thwarts the simplicity of a single administrative decision to change the system. The latter problem lies mostly in the political sphere. However, governmental bodies and other national or local council/agency fund a considerable number of studies $(43 \%$ in our review).

In terms of the modelling approach, it seems that the use of COTS packages is quite widespread, although many models are still being developed in high-level programming languages that usually have larger capabilities in accommodating complex behaviours of the system modelled. Yet, the ease of use that is offered by COTS simulation packages allows those who are not computer programmers to develop valid simulation models. This gives the opportunity to a number of people, including some stakeholders of the systems under question to engage in modelling and quantify their problems and the impact of alternative actions. However, in this way, limitations to the models are posed not only by the data availability and the computer operating cost but also by the imagination and capabilities of the modeller and the software. Simulation software costs can be high, yet since the mid-1990s, a number of low cost COTS packages have come to the market. The latter have certainly widened access to simulation (Robinson, 2005).

It is widely accepted that one of the most important results of computer simulation in healthcare, as well as in other sectors, is the increased understanding of the systems being modelled, which results from constructing the models. We 
hope that in the future it will become more imperative that healthcare modellers seek close ties and cooperation with healthcare administrators to ensure utilisation and implementation of the worthwhile models that are developed. However, the exact same anticipation was expressed some 30 years ago (England and Roberts, 1978).

As stated by Robinson (2005), simulation techniques have all followed separate paths in both research and practice until now. A closer integration among simulation techniques conjoined with advances in computing and inclusion of the World Wide Web could lead to the development of better designed models with faster execution times, high level of graphics and, most importantly, enhanced user interaction. Such an advance will be in line with the requirements of the new computer literate generation of users.

\section{Conclusions and further reflections}

This is a sample review of healthcare simulation studies, which aims at identifying healthcare problems that are modelled using four popular simulation techniques, namely MCS, DES, SD and ABS. The specific selection criteria of articles that were reviewed here may have left out a number of noble publications in the field (eg articles that do not mention health in their title topic but refer to health problems with more specific terms such as hospitals, patients, etc; articles that did not appear in journals indexed by ISI Web of Knowledge ${ }^{\circledR}$ ). The implications of this are that there may be an unintentional bias introduced by the specific keywords search and by ISI WoS membership, which leaves out newer journals that have not yet met the duration of service' required by the ISI WoS and journals where editorial boards do not wish their journal to have an impact factor. These factors may therefore not be taken into account when basing quality on impact factors. However, the debate as to whether this is right or wrong is outside the scope of this article. We merely wish to provide an analysis of literature within the scope of journals with impact factors and therefore provide some reflection as to the 'health' of healthcare simulation within a potentially metric-driven world. We hope that this study gives an indication of the pulse of research being conducted in the healthcare simulation field, although generalisation of the results may not hold.

Future research could involve a systematic review of the field including all relevant journals from various academic databases and investigate the relationships between impact factor and non-impact factor journals. This approach could more accurately map the discipline and provide us with statistics of interesting variables similar to the ones presented here and with additional ones, such as popular journals, productive institutions and frequently published authors. Future research could also broaden the scope of our literature review by profiling health-related research with the use of other OR/MS techniques.
For the benefit of healthcare and simulation audience, this paper provides an overview of research published in various journals from across different subject areas in health. This research is likely to help authors, reviewers and editors to better understand the potential of different simulation techniques for solving diverse healthcare problems and can also assist upcoming researchers in developing an appreciation of this research area and the various issues considered worthy of research and publication. Furthermore, we hope that healthcare planners, management engineers, as well as researchers will benefit from this study, by having ready access to an up-to-date, indicative collection of articles describing these applications. Finally, our study is likely to stimulate researchers to explore other research areas by undertaking comparative/cross-journal studies.

Acknowledgements - One of the authors was employed as a research fellow in Warwick Business School while working on this paper, and wishes to thank the School for supporting this research. We also thank Dr Simon J. E. Taylor for his comments, which have improved the paper.

\section{References}

Amoako-Gympah K and Meredith JR (1989). The operations management research agenda: An update. J Opns Mngt 8: 250-262.

Bagni R, Berchi R and Cariello P (2002). A comparison of simulation models applied to epidemics. JASSS 5(3).

Barrios JMR, Serrano D and Monleon T et al (2008). Discreteevent simulation models in the economic evaluation of health technologies and health products. Gac Sanit 22: 151-161.

Barton P, Bryan S and Robinson S (2004). Modelling in the economic evaluation of health care: selecting the appropriate approach. J Health Serv Res Pol 9: 110-118.

Brennan A and Akehurst R (2000). Modeling in health economic evaluation: What is its place? What is its value? Pharmacoeconomics 17: 445-459.

Dexter F (1999). Design of appointment systems for preanesthesia evaluation clinics to minimize patient waiting times: A review of computer simulation and patient survey studies. Anesth Analg 89: 925-931.

Eddama O and Coast $\mathrm{J}$ (2008). A systematic review of the use of economic evaluation in local decision-making. Health Policy 86: 129-141.

Eldabi T, Paul RJ and Taylor SJE (2000). Simulating economic factors in adjuvant breast cancer treatment. J Opl Res Soc 51: $465-475$.

Eldabi T, Paul RJ and Young T (2007). Simulation modelling in healthcare: Reviewing legacies and investigating futures. $J$ Opl Res Soc 58: 262-270.

England W and Roberts S (1978). Applications of computer simulation in health care. In: Highland HJ, Hull LG and Neilsen NR (eds). Proceedings of the 1978 Winter Simulation Conference. Institute of Electrical and Electronics Engineers: Miami Beach; Florida; USA, 4-6 December, pp 665-676.

Eveborn P, Flisberg P and Rannqvist M (2006). LAPS-CARE-an operational system for staff planning of home care. Eur J Opl Res 171: 962-976.

Fone D et al (2003). Systematic review of the use and value of computer simulation modelling in population health and health care delivery. J Public Health 25: 325-335. 
Hay JW (2004). Evaluation and review of pharmacoeconomic models Informa Pharma Sci 5: 1867-1880.

Hollocks BW (2006). Forty years of discrete-event simulation-A personal reflection. J Opl Res Soc 57: 1383-1399.

Jahangirian M, Eldabi T, Naseer A, Stergioulas LK and Young T (2009). Simulation in manufacturing and business: A review. Eur J Opl Res 203: 1-13.

Jun J, Jacobson S and Swisher J (1999). Application of discrete-event simulation in health care clinics: A survey. J Opl Res Soc 50: 109-123.

Murphy KM and Topel R (2003). The economic value of medical research. In: Measuring the Gains from Medical Research: An Economic Approachc. University of Chicago Press: Chicago, pp 41-73.

Pannirselvam GP, Ferguson LA, Ash RC and Siferd SP (1999). Operations management research: An update for the 1990s. J Opns Mngt 18: 95-112.

Pidd M (2004). Systems Modelling: Theory and Practice. John Wiley \& Sons: Chichester, England.

Robinson S (1994). Successful Simulation: A Practical Approach to Simulation Projects. McGraw-Hill Companies: Maidenhead, England.
Robinson S (2005). Discrete-event simulation: From the pioneers to the present, what next? J Opl Res Soc 56: 619-629.

Royston P (1999). The use of fractional polynomials to model continuous risk variables in epidemiology. Int $J$ Epidemiol 28: 964-974.

Rubinstein RY (1981). Simulation and the Monte Carlo Method. John Wiley \& Sons, Inc.: New York, NY, USA.

Smith-Daniels VL, Schweikhart SB and Smith-Daniels DE (1988). Capacity management in health care services: Review and future research directions. Decis Sci 19: 889-918.

Sterman JD (2001). System dynamics modelling. Calif Mngt Rev 43: 8 .

Taylor K and Lane D (1998). Simulation applied to health services: Opportunities for applying the system dynamics approach. $J$ Health Serv Res Policy 3: 226-232.

Wand Z (2009). The convergence of health care expenditure in the US states. Health Econ 18: 55-70.

Wierzbicki AP (2007). Modelling as a way of organising knowledge. Eur J Opl Res 176: 610-635.

Received October 2008; accepted January 2010 after one revision 